\title{
Analysis of plasmaspheric plumes: CLUSTER and IMAGE observations
}

\author{
F. Darrouzet ${ }^{1}$, J. De Keyser ${ }^{1}$, P. M. E. Décréau ${ }^{2}$, D. L. Gallagher ${ }^{3}$, V. Pierrard ${ }^{1}$, J. F. Lemaire ${ }^{1,4}$, B. R. Sandel ${ }^{5}$, \\ I. Dandouras ${ }^{6}$, H. Matsui ${ }^{7}$, M. Dunlop ${ }^{8}$, J. Cabrera ${ }^{4}$, A. Masson ${ }^{9}$, P. Canu ${ }^{10}$, J. G. Trotignon ${ }^{2}$, J. L. Rauch ${ }^{2}$, and \\ M. André ${ }^{11}$ \\ ${ }^{1}$ Belgian Institute for Space Aeronomy (IASB-BIRA), Brussels, Belgium \\ ${ }^{2}$ Laboratoire de Physique et Chimie de l'Environnement (LPCE), CNRS and University of Orléans, Orléans, France \\ ${ }^{3}$ Marshall Space Flight Center (MSFC), NASA, Huntsville, Alabama, USA \\ ${ }^{4}$ Center for Space Radiation (CSR), Louvain la Neuve, Belgium \\ ${ }^{5}$ Lunar and Planetary Laboratory (LPL), University of Arizona, Tucson, Arizona, USA \\ ${ }^{6}$ Centre d'Etude Spatiale des Rayonnements (CESR), CNRS, Toulouse, France \\ ${ }^{7}$ Space Science Center (SSC), University of New Hampshire, Durham, New Hampshire, USA \\ ${ }^{8}$ Space Sciences Division (SSTD), Rutherford Appleton Laboratory (RAL), Chilton, Didcot, Oxfordshire, UK \\ ${ }^{9}$ Research and Scientific Support Department (RSSD), ESTEC-ESA, Noordwijk, The Netherlands \\ ${ }^{10}$ Centre d'étude des Environnements Terrestre et Planétaires (CETP), CNRS, Vélizy, France \\ ${ }^{11}$ Swedish Institute of Space Physics (IRFU), Uppsala division, Uppsala, Sweden
}

Received: 20 October 2005 - Revised: 27 March 2006 - Accepted: 23 May 2006 - Published: 3 July 2006

\begin{abstract}
Plasmaspheric plumes have been routinely observed by CLUSTER and IMAGE. The CLUSTER mission provides high time resolution four-point measurements of the plasmasphere near perigee. Total electron density profiles have been derived from the electron plasma frequency identified by the WHISPER sounder supplemented, in-between soundings, by relative variations of the spacecraft potential measured by the electric field instrument EFW; ion velocity is also measured onboard these satellites. The EUV imager onboard the IMAGE spacecraft provides global images of the plasmasphere with a spatial resolution of $0.1 R_{E}$ every $10 \mathrm{~min}$; such images acquired near apogee from high above the pole show the geometry of plasmaspheric plumes, their evolution and motion. We present coordinated observations of three plume events and compare CLUSTER in-situ data with global images of the plasmasphere obtained by IMAGE. In particular, we study the geometry and the orientation of plasmaspheric plumes by using four-point analysis methods. We compare several aspects of plume motion as determined by different methods: (i) inner and outer plume boundary velocity calculated from time delays of this boundary as observed by the wave experiment WHISPER on the four spacecraft, (ii) drift velocity measured by the electron drift instrument EDI onboard CLUSTER and (iii) global velocity determined from successive EUV images. These different techniques consistently indicate that plasmaspheric plumes rotate
\end{abstract}

Correspondence to: F. Darrouzet

(fabien.darrouzet@oma.be) around the Earth, with their foot fully co-rotating, but with their tip rotating slower and moving farther out.

Keywords. Magnetospheric physics (Magnetospheric configuration and dynamics; Plasmasphere; Instruments and techniques)

\section{Introduction}

The plasmasphere is a toroidal region located in the Earth's magnetosphere. It is populated by cold and dense plasma of ionospheric origin. It has been investigated by satellites and ground-based instruments (see the monograph by Lemaire and Gringauz, 1998, the references cited therein, and the review by Ganguli et al., 2000). Large-scale density structures have been observed close to the outer boundary of the plasmasphere, which is called the "plasmapause" or the "Plasmasphere Boundary Layer", or PLS (Carpenter, 2004; Carpenter and Lemaire, 2004). These structures are usually connected to the main body of the plasmasphere, and extend outward. They have been called in the past "plasmaspheric tails" (Taylor et al., 1971), or, perhaps also, "detached plasma elements" (Chappell, 1974), but are now known as "plasmaspheric plumes" (e.g. Elphic et al., 1996; Ober et al., 1997; Sandel et al., 2001). Such plumes have been commonly detected by in-situ and ground-based instruments (e.g. Chappell et al., 1970; Carpenter et al., 1992; Foster et al., 2002; Moldwin et al., 2004). More recently, plumes

Published by Copernicus GmbH on behalf of the European Geosciences Union. 
have been routinely observed in global plasmaspheric images made by the Extreme Ultraviolet (EUV) imager onboard the NASA IMAGE spacecraft, sometimes compared with in-situ observations (Sandel et al., 2001, 2003; Garcia et al., 2003; Goldstein et al., 2004; Goldstein and Sandel, 2005; Spasojević et al., 2003, 2004). Plumes have also been identified in in-situ measurements of the ESA/NASA 4-spacecraft CLUSTER mission (Darrouzet et al., 2004; Décréau et al., 2004, 2005; Dandouras et al., 2005).

The formation of these plumes has been predicted on the basis of different theoretical models. Owing to the changes in the convection electric field, according to the geomagnetic activity index $K_{p}$, the plasmasphere is deformed, and parcels of plasmaspheric plasma move from the main plasmasphere towards its outer layers (Grebowsky, 1970; Chen and Wolf, 1972; Chen and Grebowsky, 1974). This has been confirmed by numerical simulations (Weiss et al., 1997). Goldstein et al. (2003a) show the importance of the evening convection enhancement associated with SAPS (Sub-Auroral Polarization Stream). The interchange instability could also play a role in the formation of plumes (Lemaire, 2000, 2001; Pierrard and Lemaire, 2004; Pierrard and Cabrera, 2005).

The purpose of this paper is to report plasmaspheric plume observations by CLUSTER. These observations are compared with global images made by IMAGE and in-situ observations by the LANL geosynchronous satellites. After presenting the instrumentation and the methods of analysis in Sect. 2, three case studies are discussed in Sect. 3. Section 4 contains a summary and conclusions.

\section{Instrumentation and methods of analysis}

\subsection{CLUSTER mission}

The four CLUSTER spacecraft (C1, C2, C3 and C4) have flown since summer 2000 in a tetrahedral configuration along similar polar orbits with a perigee of about $4 R_{E}$ (Escoubet et al., 1997). This allows CLUSTER to cross the plasmasphere from the Southern to the Northern Hemisphere every $57 \mathrm{~h}$, but the spacecraft are not penetrating deeply inside this region due to the high perigee altitude. Each CLUSTER satellite contains 11 identical instruments. Data obtained from 5 of them will be used in this paper: the electron density determined by combining data from two experiments, the Waves of HIgh frequency and Sounder for Probing Electron density by Relaxation, WHISPER (Décréau et al., 1997, 2001) and the Electric Field and Wave experiment, EFW (Gustafsson et al., 2001) (note that the electron spectrometer is usually not operating inside the plasmasphere); the ion density evaluated by the Cluster Ion Spectrometry experiment, CIS (Rème et al., 2001); the drift velocity determined by the Electron Drift Instrument, EDI (Paschmann et al., 2001); and the magnetic field measured by the FluxGate Magnetometer, FGM (Balogh et al., 2001).
The WHISPER instrument can unambiguously identify the electron plasma frequency $F_{p e}$ (related to the electron density $N_{e}$ by: $\left.F_{p e}\{\mathrm{kHz}\} \sim 9\left[N_{e}\left\{\mathrm{~cm}^{-3}\right\}\right]^{1 / 2}\right)$. In active mode, the sounder analyses the pattern of resonances triggered in the medium by a radio pulse. This allows the identification of $F_{p e}$ (Trotignon et al., 2001, 2003). In passive mode, the receiver monitors the natural plasma emissions in the frequency band $2-80 \mathrm{kHz}$. Various signatures lead to an independent estimation of $F_{p e}$ deduced from local wave cutoff properties (Canu et al., 2001).

The EFW experiment measures the spacecraft potential $V_{s c}$, which is the potential difference between the antenna probes and the spacecraft body. Using a non-linear empirical relation, which depends on the plasma regime, $N_{e}$ can be estimated from $V_{s c}$ (Pedersen, 1995; Laakso and Pedersen, 1998; Moullard et al., 2002). For a given CLUSTER perigee pass, the EFW measurements can be calibrated using the WHISPER instruments, which give absolutely calibrated values of the electron density (Pedersen et al., 2001). This calibration works well in the plasmasphere. It is, however, only possible in regions where the electron plasma frequency is below the WHISPER limit of $80 \mathrm{kHz}$, i.e, where the electron density is below $80 \mathrm{~cm}^{-3}$.

In order to facilitate inter-comparison of the four CLUSTER density profiles and comparison with projected data from IMAGE, we choose to plot the density values as a function of the equatorial distance $R_{\text {equat }}$ (in units of Earth radii): this is the geocentric distance of the magnetic field line on which the spacecraft is located, measured at the geomagnetic equator, which is identified as the location along the field line where the magnetic field strength reaches a minimum. A magnetic field model is used that combines the internal magnetic field model IGRF2000 and the external magnetic field model Tsyganenko-96 depending on the solar wind pressure, the Disturbance storm-time index $(D s t)$ and the Interplanetary Magnetic Field (IMF) $\mathrm{Y}$ and $\mathrm{Z}$ components (Tsyganenko and Stern, 1996). These models are computed with the UNILIB library (Library of routines for magnetospheric applications; http://www.oma.be/NEEDLE/unilib.php/20x/). We prefer to use $R_{\text {equat }}$ instead of the McIlwain $L$ parameter (McIlwain, 1961) because $L$ varies along a magnetic field line, except for a pure dipole, whereas $R_{\text {equat }}$ is constant along a field line by definition. Measurements made at the same $R_{\text {equat }}$ and local time therefore refer to the same magnetic flux tube.

The CIS experiment consists of two complementary spectrometers, the Hot Ion Analyser (HIA) and the COmposition and DIstribution Function analyzer (CODIF). This last sensor measures the complete 3-D distribution functions of the major ion species $\left(\mathrm{H}^{+}, \mathrm{He}^{+}, \mathrm{He}^{++}\right.$and $\left.\mathrm{O}^{+}\right)$inside the plasmasphere with a time resolution of one spacecraft spin period (4s), from which partial densities and $\mathrm{H}^{+}$velocities can be computed. In addition CODIF contains in the aperture system an additional Retarding Potential Analyser (RPA) device with pre-acceleration for energies between 0.7 and $25 \mathrm{eV} / \mathrm{q}$, 
with respect to the spacecraft potential. CODIF works in this RPA mode on $\mathrm{C} 1, \mathrm{C} 3$, and $\mathrm{C} 4$.

The EDI experiment measures the drift velocity of artificially injected electron beams. Two beams are emitted in opposite directions perpendicular to the magnetic field, and return to their associated detectors after one or more gyrations. The drift velocity is derived from the directions of the received beams and from the difference in their timesof-flight. This instrument works on $\mathrm{C} 1, \mathrm{C} 2$, and $\mathrm{C} 3$. The data used in this study have been cleaned and smoothed as described by Matsui et al. $(2003,2004)$.

The FGM instrument consists of two tri-axial fluxgate magnetometers and an on-board data-processing unit. It provides high time resolution $(22.4 \mathrm{~Hz}$ in normal mode) magnetic field measurements from all four spacecraft with an accuracy of at least $0.1 \mathrm{nT}$. The data have been time-averaged to a resolution of $4 \mathrm{~s}$.

\subsection{IMAGE mission and LANL satellites}

The IMAGE (Imager for Magnetopause-to-Aurora Global Exploration) spacecraft was launched in March 2000 into a polar orbit with a perigee of $7400 \mathrm{~km}$ and an apogee of $8.2 R_{E}$ (Burch, 2000). The Extreme Ultraviolet (EUV) imager onboard IMAGE provides global images of the plasmasphere (Sandel et al., 2000). It is an imaging system composed of three cameras, which detect the $30.4 \mathrm{~nm}$ sunlight resonantly scattered by the $\mathrm{He}^{+}$ions in the plasmasphere. It provides a global image of the plasmasphere every $10 \mathrm{~min}$ with a spatial resolution of $0.1 R_{E}$. Thanks to IMAGE's high apogee and EUV's wide field of view, these images show the structure of the entire plasmasphere. Sequences of such 2$\mathrm{D}$ images show the evolution and motion of plasmaspheric plumes over time. The azimuthal and radial velocity of different parts of a plume (the foot or the tip for example) can be quantified from a comparison of the position of plume elements between successive images.

For better comparison with CLUSTER data, the EUV images have been projected onto the dipole magnetic equatorial plane, by assigning to each pixel the minimum dipole $L$-shell along the line-of-sight (Roelof and Skinner, 2000; Goldstein et al., 2003b; Gallagher et al., 2005). L-based mapping has been chosen as EUV images show the plasmasphere close to Earth, where the dipole magnetic field can be used (for low to moderate geomagnetic activity). The mapped signal is then converted to column abundance using estimates for the solar flux at $30.4 \mathrm{~nm}$, based on the SOLAR2000 empirical solar irradiance model (Tobiska et al., 2000). Finally, the column abundance is converted to pseudo-density by dividing by an estimate of the distance along the line-of-sight that contributes most to the image intensity at each location in the field of view (for more details, see Gallagher et al., 2005). Therefore the EUV images shown in this paper give an equatorial distribution of $\mathrm{He}^{+}$pseudo-density versus $L$ and Magnetic Local Time (MLT). The lower sensitivity threshold of the EUV instrument has been estimated to be $4-8 \mathrm{He}^{+}$ions $\mathrm{cm}^{-3}$, or $40 \pm 10 \mathrm{H}^{+}$electrons $\mathrm{cm}^{-3}$ if assuming a ratio $\mathrm{He}^{+} / \mathrm{H}^{+}$around $0.1-0.2$ (Goldstein et al., 2003b).

The EUV images have been reprocessed to filter away the noise (apparent as high frequency spatial variations in the image) based on the fact that small scale density distribution in the plasmasphere is not accessible to the instrument, due to its intrinsic resolution and because emission intensities in the EUV images are line-of-sight integration. To increase the signal/noise ratio, we have binned the images $(2 \times 2$ bins) and subsequently smoothed them (low band pass spatial filter). Finally, we have used histogram equalization and an appropriate colour scale to improve the contrast of the images.

The Magnetospheric Plasma Analyser (MPA) instruments onboard the Los Alamos National Laboratory (LANL) geosynchronous satellites measure the ion density in the range $1-130 \mathrm{eV} / \mathrm{q}$ (Bame et al., 1993). This energy range does not cover the coldest fraction of the plasmaspheric distribution, as for the CIS instrument onboard the CLUSTER satellites. However, as the spacecraft potential is typically slightly negative in the dense plasmaspheric plasma, the full ion distribution is slightly accelerated into the instrument. Then the energy resolution is not quite adequate to resolve the distribution well, but nothing is hidden by the potential.

\subsection{Spatial gradient}

We compute the spatial gradient of different scalar quantities along the trajectory of the centre of mass of the CLUSTER tetrahedron. The method described by Harvey (1998) and Darrouzet et al. (2006) is used. The gradient is determined from simultaneous measurements of a given scalar quantity, with the hypothesis that all four spacecraft are embedded in the same structure at the same time. The three events presented in this paper are small spacecraft separation cases, prone to meet this constraint of quasi-homogeneity in space. This tool can be applied in particular to the electron density and to the magnetic field components. However, it crucially depends on the inter-spacecraft separation, the time resolution and the measurement accuracy on all four spacecraft. The limitations of this technique are discussed by Darrouzet et al. (2006).

\subsection{Velocities}

To study the motion of plasmaspheric plumes with CLUSTER, we use velocities determined from different techniques. The $\mathrm{H}^{+}$velocity $\boldsymbol{V}_{H}$ can in principle be determined from the ion distribution functions measured with the CIS/CODIF instrument. The accuracy of the velocity measurements in the plumes is limited by low particle counts (due to the low density in the plumes) and is further influenced by spacecraft charging (outside the main plasmasphere the spacecraft potential can become strongly positive) and the finite energy 

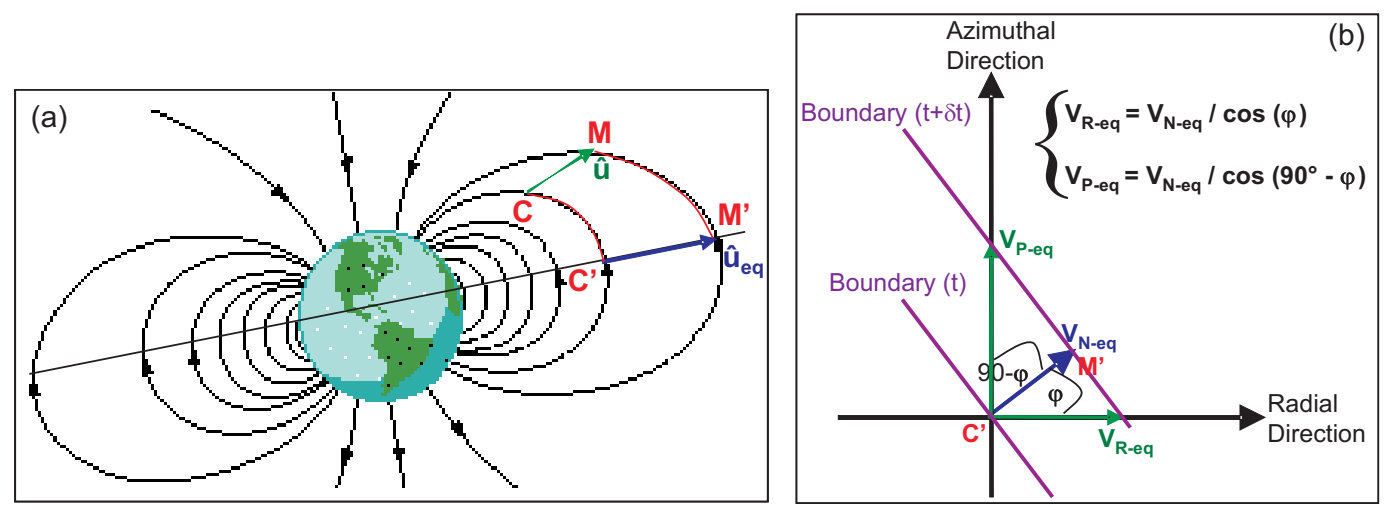

Fig. 1. (a) Projection along the magnetic field line of a vector $\boldsymbol{u}$ determined at the centre of mass $\mathrm{C}$ of the four satellites, until the magnetic field strength reaches a minimum $\left(\mathrm{C}^{\prime}\right): \boldsymbol{u}_{e q}$. (b) Definition of three velocity vectors in the equatorial plane: the normal boundary velocity $\boldsymbol{V}_{N-e q}$, the azimuthal plasma velocity $\boldsymbol{V}_{P-e q}$ and the apparent radial boundary velocity $\boldsymbol{V}_{R-e q}$ (see text for more details).

Table 1. Summary of the different types of velocity.

\begin{tabular}{|c|c|c|c|}
\multicolumn{5}{|c}{ Measured Velocities: } \\
\hline Acronym (Instrument) & $\mathrm{V}_{\mathrm{D}}(\mathrm{EDI})$ & $\mathrm{V}_{\mathrm{E}}(\mathrm{EUV})$ & $\mathrm{V}_{\mathrm{C}}$ \\
\hline Name & Electron drift velocity & Global velocity & Co-rotation velocity \\
\hline
\end{tabular}

\begin{tabular}{|c|c|c|c|c|}
\hline \multicolumn{1}{|c|}{ Computed Velocities: } \\
$\begin{array}{c}\text { Acronym } \\
\text { (Instrument) }\end{array}$ & $\begin{array}{c}\mathrm{V}_{\mathrm{N}} \\
\text { (WHISPER) }\end{array}$ & $\begin{array}{c}\mathrm{V}_{\mathrm{P}} \\
\text { (WHISPER) }\end{array}$ & $\begin{array}{c}\mathrm{V}_{\mathrm{R}} \\
\text { (WHISPER) }\end{array}$ & $\begin{array}{c}\mathrm{V}_{\mathrm{IO}} \\
\text { (WHISPER) }\end{array}$ \\
\hline Name & $\begin{array}{c}\text { Normal boundary } \\
\text { velocity } \\
\text { plasmathal } \\
\text { velocity }\end{array}$ & $\begin{array}{c}\text { Apparent } \\
\text { radial } \\
\text { boundary } \\
\text { velocity }\end{array}$ & $\begin{array}{c}\text { Average radial } \\
\text { velocity between } \\
\text { inbound and outbound } \\
\text { structure }\end{array}$ \\
\hline Assumption & $\begin{array}{c}\text { Same structure } \\
\text { crossed in the } \\
\text { same time by the } \\
\text { four satellites }\end{array}$ & $\begin{array}{c}\text { Azimuthal } \\
\text { motion only }\end{array}$ & $\begin{array}{c}\text { Azimuthal } \\
\text { motion only }\end{array}$ & $\begin{array}{c}\text { Same MLT sector } \\
\text { between both structure } \\
\text { crossings }\end{array}$ \\
\hline
\end{tabular}

range of the instrument. We therefore have not used these velocities.

The electron drift velocity $\boldsymbol{V}_{D}$ is measured by EDI and is available from each spacecraft on which this instrument is operating.

A four-point technique, called time-delay, is applied to the features (supposed to be locally planar boundaries) identified in the WHISPER electron density profiles at the inner and outer boundary of the plumes. Assuming a boundary to be a planar surface travelling at a constant velocity along its normal, we determine the normal boundary velocity $\boldsymbol{V}_{N}$ with a time delay method, i.e. from individual spacecraft positions and times of the boundary crossings.

We compute also the co-rotation velocity at the centre of mass of the four CLUSTER spacecraft: $V_{C}=2 \pi R /(24 \times 60 \times 60)$, where $R$ is the distance from the spacecraft to the Earth's rotation axis.

An average radial velocity, $V_{I O-e q}$, can be computed from the displacement in $R_{\text {equat }}$ of a structure between in- and outbound passes, when the spacecraft remains approximately in the same MLT sector.
From IMAGE data, we determine another velocity: the azimuthal and radial motion $V_{E}$ of geometrically identified parts of the plume as determined from successive EUV images projected onto the dipole magnetic equatorial plane.

\subsection{Mapping onto magnetic equatorial plane}

We project all the CLUSTER vector measurements (velocities, normals and spatial gradients) onto the magnetic equatorial plane by using the same magnetic field model as in the WHISPER density analysis (IGRF2000 and Tsyganenko-96). If we have a vector $\boldsymbol{u}$ determined at the centre of mass $C$ of the four spacecraft, we consider a small displacement (of the order of a few kilometres) of this point $\mathrm{C}$ to $\mathrm{M}$ with the velocity $\boldsymbol{u}$. We determine the projection $\mathrm{C}^{\prime}$ of $\mathrm{C}$ along the magnetic field line, until the magnetic field strength reaches a minimum. By doing the same with point $\mathrm{M}$, we determine the velocity $\boldsymbol{u}_{e q}$ in the magnetic equatorial plane. This technique is shown on Fig. 1a (for the simple case of a dipole field). We thus obtain the following velocities: $\boldsymbol{V}_{H-e q}, \boldsymbol{V}_{D-e q}, \boldsymbol{V}_{N-e q}, V_{C-e q}$, all without any component 


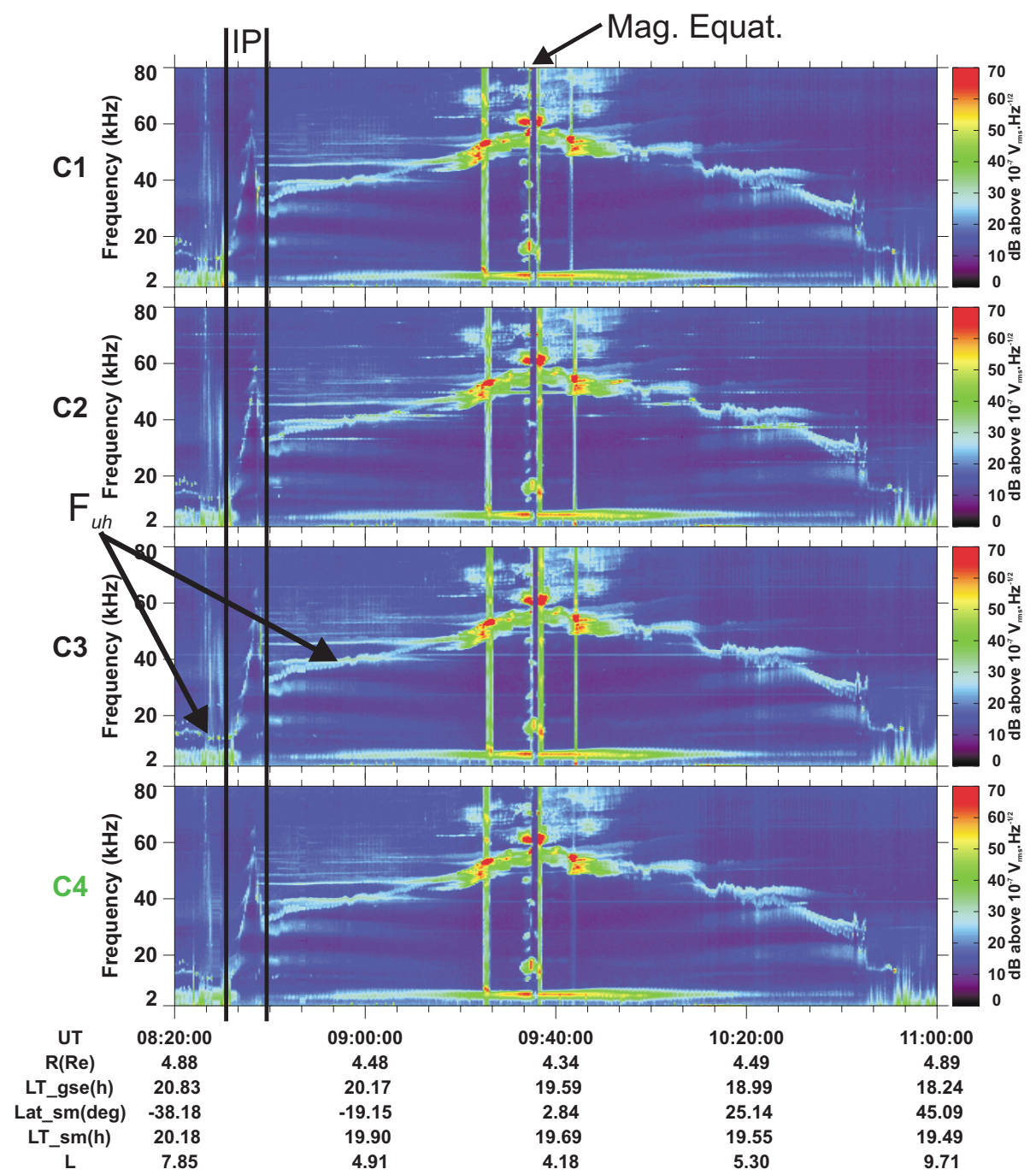

Fig. 2. Frequency-time spectrograms measured on 7 May 2002 by the WHISPER instrument onboard the four CLUSTER spacecraft. The entire plasmasphere crossing is shown, including a plume crossing during the inbound pass (IP) and the magnetic equator (Mag. Equat.) crossed at 09:35 UT. The upper hybrid frequency, $F_{u h}$, is indicated by the black arrows. The orbital parameters correspond to C4.

in the magnetic field direction. Then we derive the azimuthal and radial components of all those velocities.

Let us assume that the plasma is rotating, i.e. moving in the azimuthal direction only. Figure $1 \mathrm{~b}$ shows how a boundary frozen into the plasma moves as the plasma rotates, with an azimuthal plasma velocity $V_{P-e q}$, from its position at time $\mathrm{t}$ to its position at time $t+\delta$ t. If we define the angle $\phi$ between the normal boundary velocity and the radial direction, this motion implies that $V_{N-e q}=V_{P-e q} \sin \phi$, which is the normal boundary velocity we actually measure. The azimuthal plasma velocity $V_{P-e q}$ can then be deduced and compared to the full co-rotation speed $V_{C-e q}$. The apparent radial boundary velocity, $V_{R-e q}$, corresponding to the apparent radial motion of the boundary when observed at fixed MLT, is: $V_{R-e q}=\mathrm{V}_{N-e q} / \cos \phi$ (see panel (b) of Fig. 1). All those velocities are summarized in Table 1.

\section{Observations}

\subsection{First event: 7 May 2002}

\subsubsection{CLUSTER observations}

This plasmasphere crossing is located around 20:00 MLT on 7 May 2002 and with a maximum value of $K_{p}$ in the previous $24 \mathrm{~h}$ equal to 3 . The CLUSTER spacecraft separation distance is small (around $150 \mathrm{~km}$ ). Figure 2 displays frequencytime spectrograms from the four WHISPER instruments during the entire plasmasphere crossing. The magnetic equator is crossed by all four spacecraft at almost the same time, around 09:35 UT, as indicated by the presence of intense monochromatic electrostatic wave emissions. The upper hybrid frequency, $F_{u h}$ increases from $15 \mathrm{kHz}$ to $50-60 \mathrm{kHz}$ during the inbound part of the crossing and decreases down to 


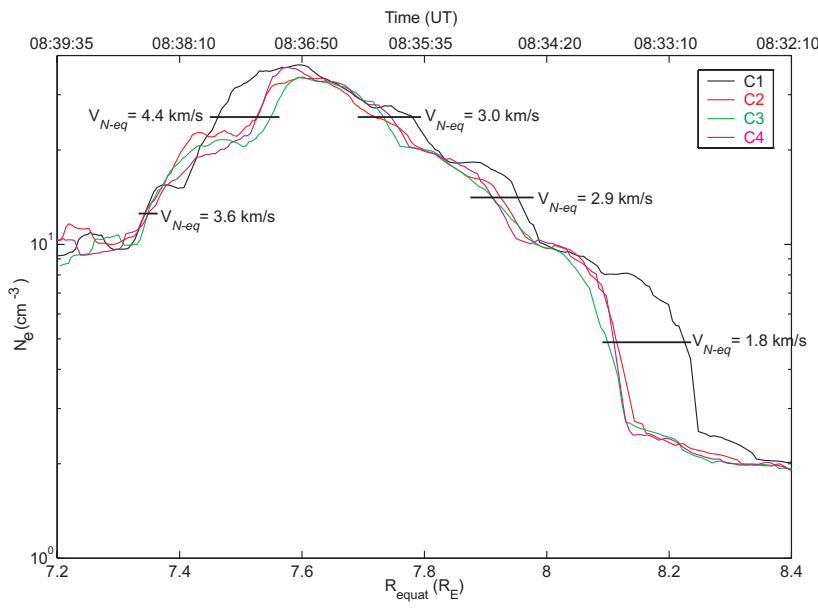

Fig. 3. Electron density profiles for the four CLUSTER satellites as a function of $R_{\text {equat }}$ across the plume observed on 7 May 2002 (time indicated as reference). The magnitude of the normal boundary velocity vectors $\boldsymbol{V}_{N-e q}$ derived from the time delays at different times during the crossing and projected onto the magnetic equatorial plane is indicated on the figure.

$15 \mathrm{kHz}$ again during the outbound part. This quantity, associated with the electron gyro-frequency, $F_{c e}$ detected by the sounder, allows the determination of the electron plasma frequency, $F_{p e}$, through the relation: $F_{p e}=\left(F_{u h}^{2}-F_{c e}^{2}\right)^{1 / 2}$, and therefore the electron density $N_{e}$. The spacecraft cross the plasmasphere, but they are not going deeply inside this region, as confirmed by the rather low maximum value of $F_{p e}$ (the maximum of $60 \mathrm{kHz}$ corresponds to an electron density of only $45 \mathrm{~cm}^{-3}$ ). A density structure is observed in the inbound pass by all satellites around 08:35 UT. IMAGE data presented in the following section will confirm that this structure is a plasmaspheric plume (labelled IP on the figure, for "inbound plume"). A small increase in the plasma frequency is also seen during the outbound crossing around 10:45 UT.

The electron density profiles as a function of time look very similar, thus the assumption of a locally planar surface used in four-point methods is justified in this case. However, on the profiles shown as a function of $R_{\text {equat }}$ for the inbound plume crossing in Fig. 3, C1 observes the outer region of the plume a bit further outward. The differences could come from the different latitudes of the spacecraft (which could explain systematic difference in density) and the outward motion of the density structure during the time interval ( $\mathrm{C} 1$ crosses the plume about $1 \mathrm{~min}$ ahead of the 3 other spacecraft). Moreover, the satellites do not cross this structure in exactly the same MLT sector, which can explain such a shift if the orientation of the density interface is not perfectly parallel to a magnetic shell. Finally, the order of the plume crossing-times by the four spacecraft is the same in the inner edge and in the outer edge (Fig. 6d). This is consistent with the structure moving gradually with respect to the spacecraft. We use the time delay method to determine the normal ve- locities of the plume boundaries and the method presented in Sect. 2.5 to determine their projection onto the magnetic equatorial plane. The outer boundary of the plume is moving at $V_{N-e q}=2.3 \pm 0.5 \mathrm{~km} / \mathrm{s}$. The angle $\phi$ between the normal of the outer boundary (determined from the spatial density gradient direction and from the normal boundary velocity direction) and the radial direction is around $15^{\circ}$. If the plasma would move only azimuthally, this would imply an equatorial azimuthal plasma velocity $V_{P-e q}=8.8 \pm 2.0 \mathrm{~km} / \mathrm{s}$. This is much higher than the co-rotation speed $V_{C-e q}=3.7 \mathrm{~km} / \mathrm{s}$. The azimuthal speed could be smaller if there would also be some outward plasma motion, e.g. for the outer edge, $V_{P-e q}=3.7 \mathrm{~km} / \mathrm{s}$ and $V_{R-e q}=1.3 \mathrm{~km} / \mathrm{s}$ would also be compatible with $V_{N-e q}=2.3 \mathrm{~km} / \mathrm{s}$ and $\phi \sim 15^{\circ}$. The inner boundary, around 08:38 UT moves with $V_{N-e q}=3.6 \pm 0.5 \mathrm{~km} / \mathrm{s}$. With $\phi \sim 30^{\circ}$, this gives $V_{P-e q}=7.2 \pm 1.0 \mathrm{~km} / \mathrm{s}$, which is also higher than $V_{C-e q}(3.3 \mathrm{~km} / \mathrm{s})$. This suggests that there are deviations from co-rotation, with the outer boundary moving faster than the inner edge.

Figure 4 presents energy-time spectrograms from the CIS instrument in RPA mode, which measures the ion distribution in the energy band $0.7-25 \mathrm{eV} / \mathrm{q}$ with respect to the spacecraft potential (usually between 1 and $2 \mathrm{eV}$ in the plasmasphere). Panels (a), (b) and (c) are respectively for $\mathrm{H}^{+}, \mathrm{He}^{+}$ and $\mathrm{O}^{+}$, and panel (d) is the pitch-angle distribution of $\mathrm{H}^{+}$. The plume IP is observed between 08:36 and 08:38 UT. It is mainly composed of protons, which have isotropic flux, traces of $\mathrm{He}^{+}$and no detectable $\mathrm{O}^{+}$ions. The density values obtained from CIS in the inbound plume are smaller than those from the WHISPER experiment, because the spectrometer does not detect particles below $0.7 \mathrm{eV}$ (with respect to the spacecraft potential), which is the major fraction of the distribution (Dandouras et al., 2005).

The projected electron drift velocity $\boldsymbol{V}_{D-e q}$ from EDI is plotted as a function of time on Fig. 5 for the satellites C1, $\mathrm{C} 2$ and $\mathrm{C} 3$, during the inner plasmasphere crossing. The azimuthal and radial velocity components, plotted respectively on panels (a) and (b), have a wavy structure during almost all the inner plasmasphere crossing, with a period of about $100 \mathrm{~s}$. Such oscillations are not seen in the density profiles; these non-compressional oscillations could be Alfvén waves. When the spacecraft are inside the plasmasphere, between 09:00 and 10:10 UT (i.e. $R_{\text {equat }}$ below $6 R_{E}$ ), the average drift velocity magnitude is $V_{D-e q}=2.1 \pm 0.2 \mathrm{~km} / \mathrm{s}$, close to the co-rotation velocity $V_{C-e q}=2.2 \pm 0.2 \mathrm{~km} / \mathrm{s}$, and its direction is also essentially azimuthal. Between this region and the plume (08:40-09:00 UT), the plasma is moving in the anti co-rotation direction, which is not surprising at such distance from the Earth (6-7 $\left.R_{E}\right)$, where the co-rotation electric field has less influence. These results confirm that the inner plasmasphere is mainly in co-rotation around the Earth.

Figure 6 shows a zoom on the plume crossing time interval, with EDI drift velocities on panels (a), (b), (c) and WHISPER electron density displayed on panel (d). For the outer part of the plume (between 08:32 UT and 08:37 UT), 


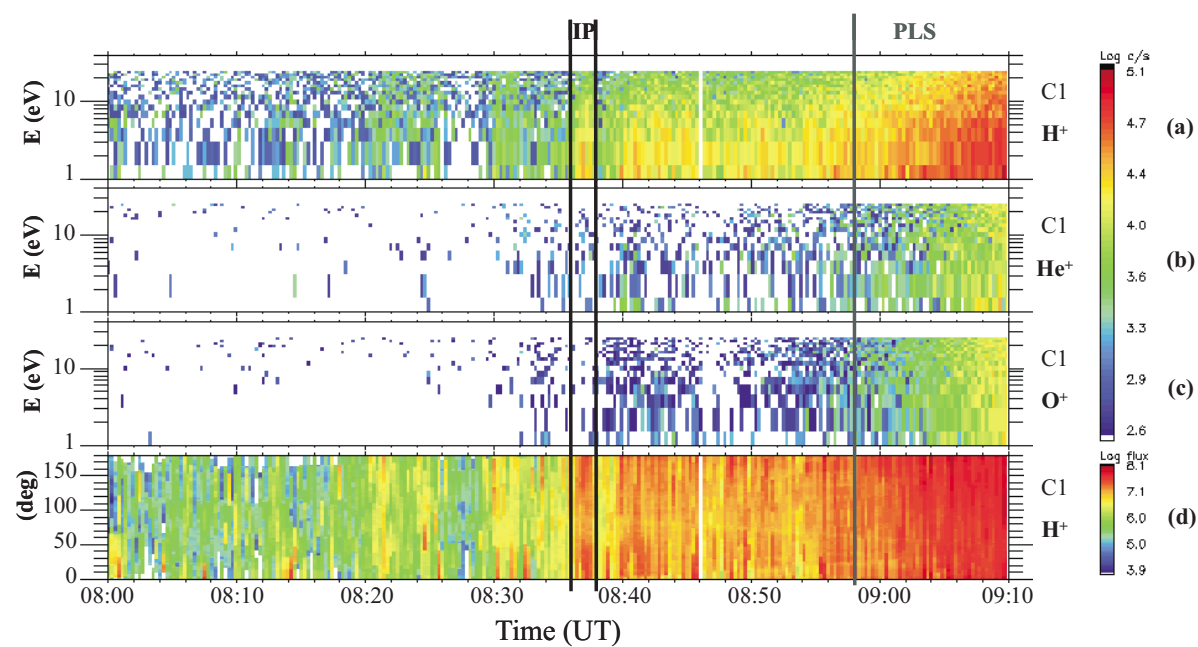

Fig. 4. Energy-time spectrograms from the CIS instrument in RPA mode on 7 May 2002 during the inbound crossing by C1 (IP means "Inbound Plume"; PLS means "Plasmasphere"). Panels (a), (b) and (c) are for $\mathrm{H}^{+}, \mathrm{He}^{+}$and $\mathrm{O}^{+}$ions respectively, and panel (d) is the pitch-angle distribution of $\mathrm{H}^{+}$.

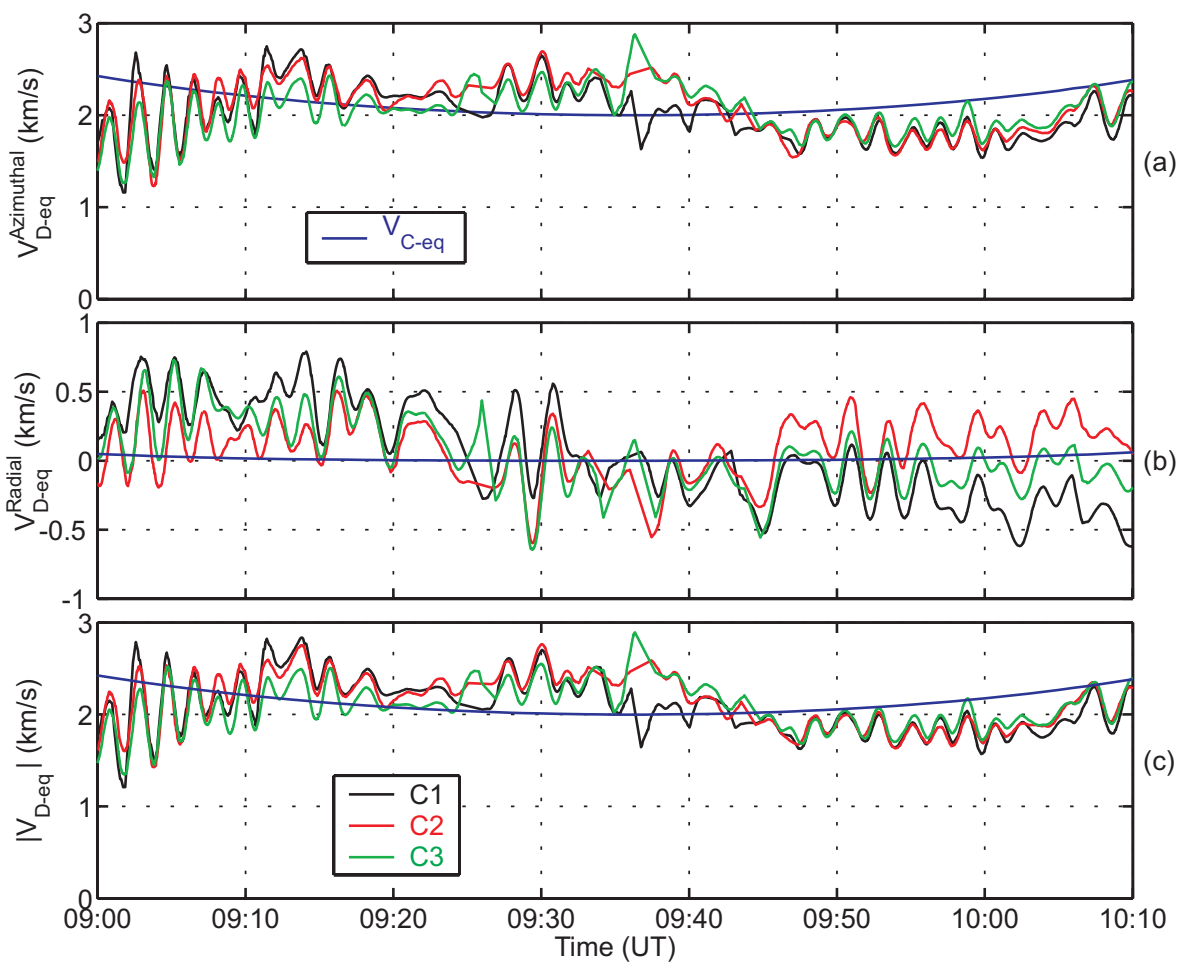

Fig. 5. Electron drift velocity $\boldsymbol{V}_{D-e q}$ measured by EDI and projected onto the magnetic equatorial plane plotted in azimuthal (a), radial (b) and magnitude (c) coordinates as a function of time for C1, C2 and C3 during the plasmasphere crossing of 7 May 2002, with the co-rotation velocity $\boldsymbol{V}_{C-e q}$ also projected onto the same plane (blue lines).

$\boldsymbol{V}_{D-e q}$ is azimuthal and radial $(\sim 2.5 \mathrm{~km} / \mathrm{s})$ with an average magnitude much higher than the co-rotation speed $\left(V_{D-e q}=8.5 \pm 1.0 \mathrm{~km} / \mathrm{s}\right.$ whereas $\left.V_{C-e q}=3.8-3.4 \mathrm{~km} / \mathrm{s}\right)$. However, in the density gradient of the plume closest to the plasmasphere (between 08:37 and 08:39 UT), the drift velocity is closer to the co-rotation velocity, in terms of direction and magnitude.

By looking at the magnetic field $\boldsymbol{B}$ measured by the FGM experiment (shown on panels (e)-(h) of Fig. 6), we observe variations in magnetic field orientation during the plume 

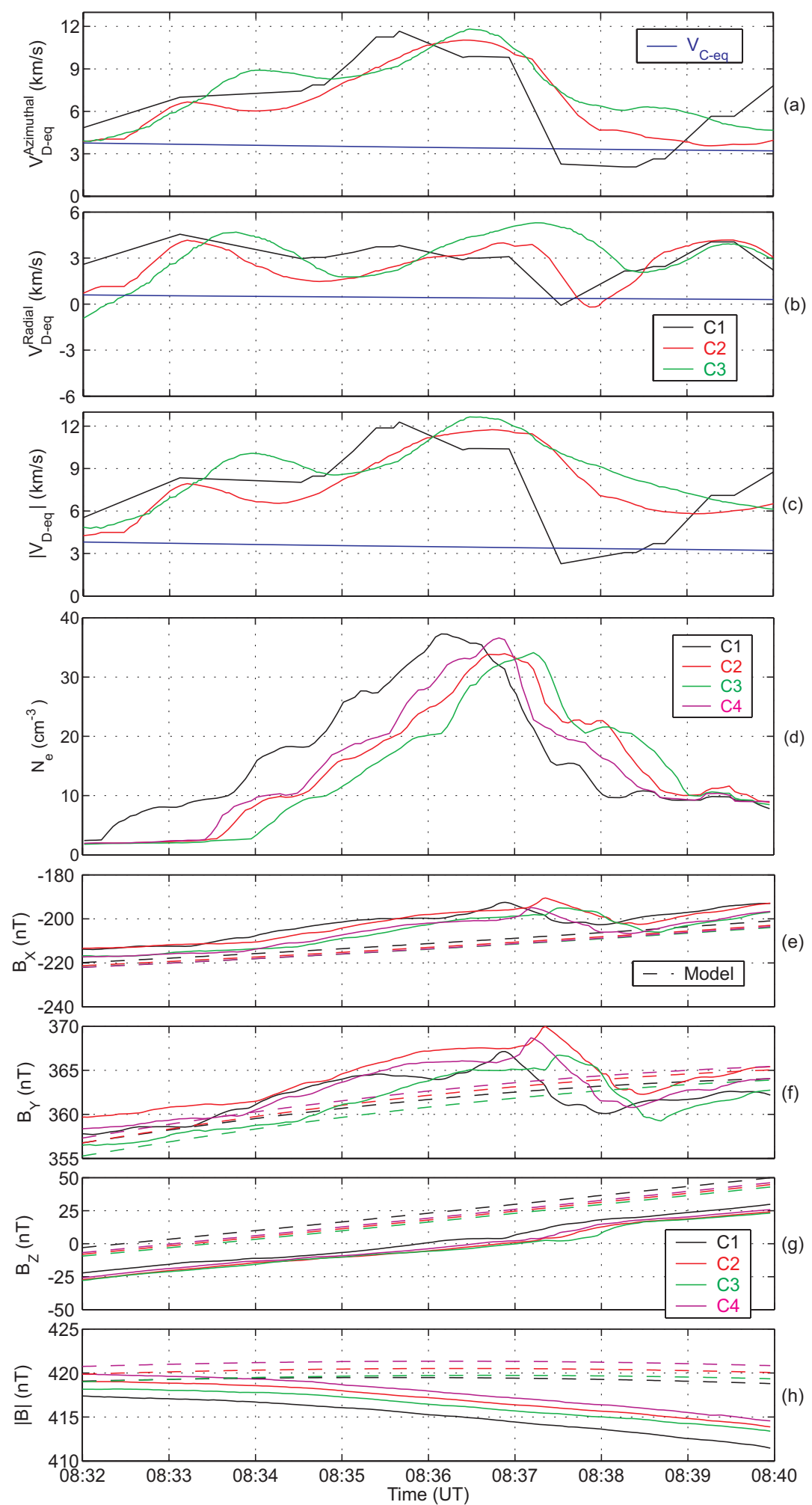

Fig. 6. Different quantities plotted as a function of time during the inbound plume crossing of 7 May 2002: (a)-(c) electron drift velocity measured by EDI and projected onto the magnetic equatorial plane (similar as Fig. 5); (d) electron density determined by WHISPER; (e)-(h) magnetic field components and magnitude in the GSE coordinate system measured by FGM (in solid lines) and determined from IGRF2000 and Tsyganenko-96 models (in dotted lines). 
crossing, but no variation in magnitude. There is a gradual rotation of $\boldsymbol{B}$ of about $5^{\circ}$ up to the time of the maximum density of the plume (08:34-08:37 UT), and then $\boldsymbol{B}$ turns back rapidly to its original orientation (08:37-08:39 UT).

\subsubsection{IMAGE and LANL observations}

Figure 7 shows an EUV image of the plasmasphere at 08:31 UT on 7 May 2002 (around the time of the inbound crossing of the plume by CLUSTER). This image is a full frame image, reduced to the region of interest, and projected onto the dipole magnetic equatorial plane using the method described in Sect. 2.2. The Sun is toward the right in this picture and the size and location of the Earth are indicated by the white disk in the centre of the image; the Earth's shadow extends through the plasmasphere in the anti-sunward direction. The CLUSTER spacecraft are located at 20:00 MLT, in the top-left corner of the image. The two white lines correspond to the limit between the three EUV cameras, where the density level could be decreased or increased by this artefact.

A thin but extended plume is observed on this EUV image, from the evening sector (20:00 MLT) to the post-midnight sector (01:00 MLT). The plume is not very clearly seen on the figure, because of its level of density (maximum value of $40 \mathrm{~cm}^{-3}$ from WHISPER) close to the EUV threshold ( $40 \pm 10$ electrons $\mathrm{cm}^{-3}$ ), but by looking at image sequences, we can clearly see the global shape of the plume. The EUV image shows that the centre of the plume extends from $5.5 R_{E}$ at its foot to $7.7 R_{E}$ at its tip, and that its transverse size has a maximum extent of about $0.7 R_{E}$. At $08: 31 \mathrm{UT}$ and 20:00 MLT, it is located between 7.0 and 7.7 $R_{E}$ in the line-of-sight integrated images, which is consistent with the plume observed by WHISPER between 08:32 and 08:40 UT at 20:00 MLT with $R_{\text {equat }}$ between 7.3 and 8.2 $R_{E}$. Between 18:00 and 20:00 MLT, the plasmapause is located between 4 and $3.7 R_{E}$ on the EUV image. From CLUSTER data, it is difficult to distinguish the plasmapause, as the spacecraft does not completely enter the plasmasphere, but we could at least say that around 20:00 MLT the plasmapause is at a distance less than $4.2 R_{E}$.

The plume is observed on EUV images for the first time around 04:00 UT, with its foot attached to the plasmasphere around 20:00 MLT. It is visible until 10:00 UT, at which time the foot is located around 01:30 MLT. Before and after this time interval, EUV images are not of sufficient quality, or IMAGE is too close to the Earth to view the entire plasmasphere. These values give an approximate motion of the foot of the plume (at $4 R_{E}$ ) of the order of the co-rotation velocity $V_{C-e q}=1.9 \mathrm{~km} / \mathrm{s}$ there. However, with the same kind of analysis near the tip of the plume, between 07:20 and 09:20 UT, we find a velocity of the order of half the co-rotation velocity, with a slight increase in radial distance of the order of $0.3 R_{E}$ over this period of time (i.e. outward speed of $\sim 0.3 \mathrm{~km} / \mathrm{s}$ ). This means that the plume is rotating around the Earth, with its foot attached to the main plasmasphere where it is co-

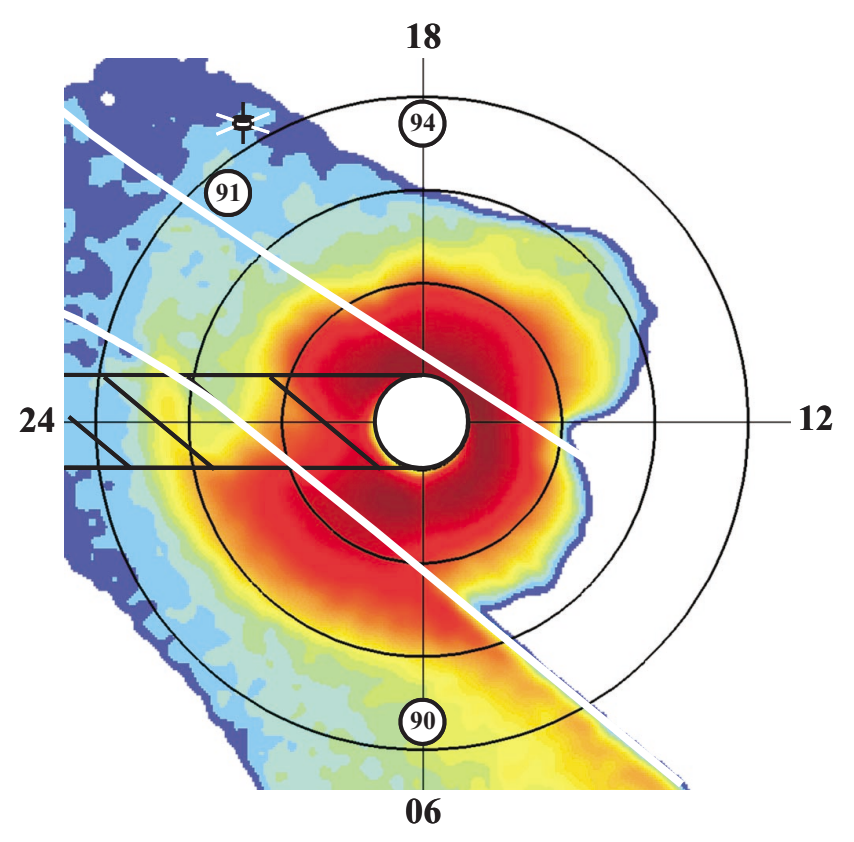

Fig. 7. Projection of a full-frame EUV image onto the equatorial plane at 08:31 UT on 7 May 2002. The white disk in the centre of the image corresponds to the size and position of the Earth, with its shadow extending away from the Sun. The three large circles correspond to $R_{\text {equat }}=3,5$ and $7 R_{E}$. The two white lines correspond to the limits between the three EUV cameras. The position of the CLUSTER satellites is indicated on the EUV image, as well as the positions of three geosynchronous satellites: LANL 1990095, LANL 1991-080 and LANL 1994-084.

rotating, but with its tip rotating more slowly and moving farther away from the Earth. This is consistent with the results obtained with the CLUSTER velocities described in the previous section, and with earlier studies of plasmaspheric plumes (Spasojević et al., 2003; Darrouzet et al., 2004).

The geosynchronous satellites LANL 1991-080 and LANL 1994-084 observe an increase of ion density in the same region as CLUSTER and IMAGE: LANL 1991-080 records up to $35 \mathrm{~cm}^{-3}$ around 09:00-09:30 UT at 22:00 MLT and LANL 1994-084 up to $35 \mathrm{~cm}^{-3}$ around 11:00-11:15 UT at 21:00 MLT. LANL 1990-095, located around 06:00 MLT at 08:30 UT, does not observe any density structure (the positions of the three spacecraft are indicated on Fig. 7). These observations confirm the presence of a narrow plume with a low density maximum, around $7 R_{E}$, in the pre-midnight MLT sector.

\subsection{Second event: 2 June 2002}

\subsubsection{CLUSTER observations}

This second event is observed with small spacecraft separation (around $150 \mathrm{~km}$ ), in the dusk sector (18:00 MLT), and when the geomagnetic activity had a peak value of $K_{p}=4$ 


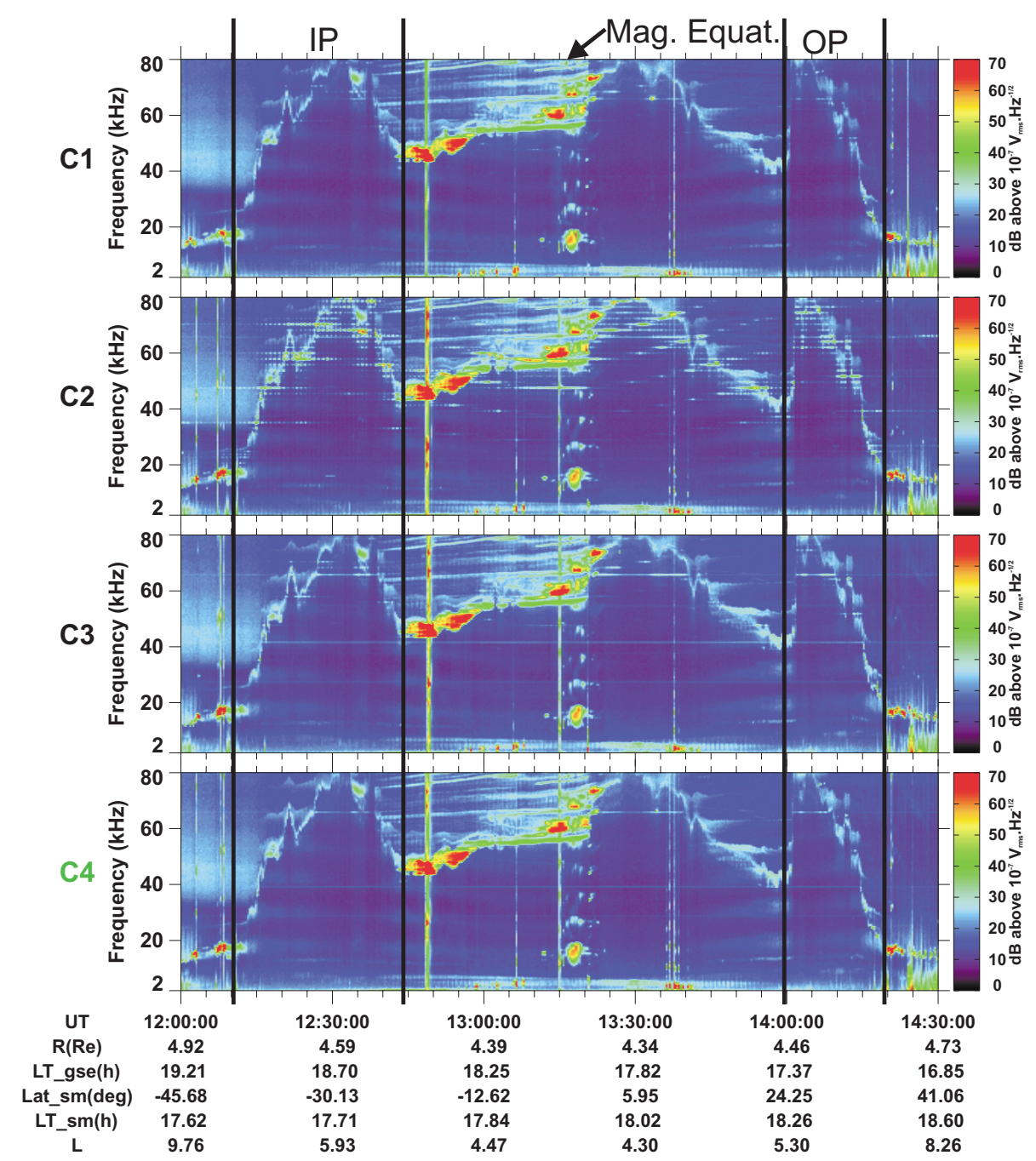

Fig. 8. Frequency-time spectrograms measured by the four CLUSTER/WHISPER instruments on 2 June 2002, showing the entire plasmasphere crossing, including plume traversals in the inbound (IP) and outbound passes (OP) and the magnetic equator (Mag. Equat.) crossed around 13:20 UT. The orbital parameters correspond to C4.

in the previous $24 \mathrm{~h}$. Figure 8 displays WHISPER spectrograms. The magnetic equator is crossed around 13:20 UT. A very wide plume is seen in the inbound (IP) and outbound passes (OP) on all four spacecraft; the IP lasts more than $30 \mathrm{~min}$. The plume crossings are almost identical on the four satellites (see for example, the small structure inside IP at 12:20 UT, and an OP structure at 14:10 UT). This plume has a high maximum $F_{p e}$, slightly above $80 \mathrm{kHz}$.

The electron density profiles of the plume as determined from WHISPER and EFW (for the part above $80 \mathrm{~cm}^{-3}$ ) are shown in Fig. 9. Both structures have the same overall shape. This indicates that these are crossings of the same plume at Southern and Northern latitudes of the plasmasphere. The similarity of the profiles between IP and OP suggests that the plume has not moved much over the $2 \mathrm{~h}$ between IP and OP. This is confirmed by the equatorial normal boundary ve- locities $V_{N-e q}$ derived from the time profiles and shown on Fig. 9. These velocities are quite small for the inbound plume crossing (larger at the outer edge than at the inner one). The angle $\phi$ between the normal of the outer boundary of the inbound crossing and the radial direction (determined from the spatial density gradient direction and from the normal boundary velocity direction) is around $10^{\circ}, V_{N-e q}=1.2 \pm 0.7 \mathrm{~km} / \mathrm{s}$, and then $V_{P-e q}=6.9 \pm 1.2 \mathrm{~km} / \mathrm{s}$ with the assumption that the velocity is azimuthal without any radial component. This is much higher than the co-rotation velocity, $V_{C-e q}$, which is between 3.6 and $2.8 \mathrm{~km} / \mathrm{s}$ at these spacecraft positions. This could be also compatible with a lower azimuthal speed if there is an outward plasma motion as well. At the inner edge, $\phi \sim 10^{\circ}, V_{N-e q}=0.7 \pm 0.2 \mathrm{~km} / \mathrm{s}$, and thus $V_{P-e q}=4.0 \pm 1.2 \mathrm{~km} / \mathrm{s}$, also higher than $V_{C-e q}$. For the outbound crossing, the boundary velocities are very different 


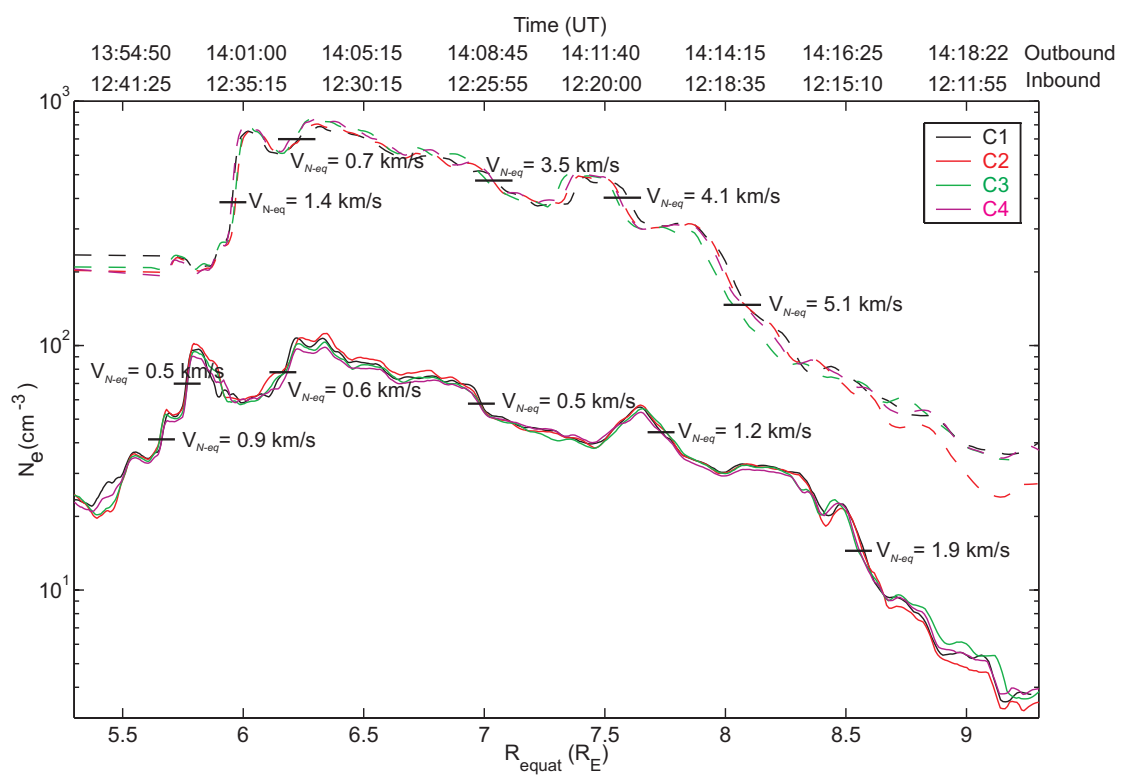

Fig. 9. Electron density profiles as a function of $R_{\text {equat }}$ for the two plume crossings on 2 June 2002 (time indicated as reference). The lower four curves correspond to the inbound pass and the upper four curves (shifted by a factor 10) to the outbound pass by the four CLUSTER satellites. The magnitude of the normal boundary velocity $\boldsymbol{V}_{N-e q}$ derived from the time delays of different features during both plume crossings and projected onto the magnetic equatorial plane is indicated on the figure.

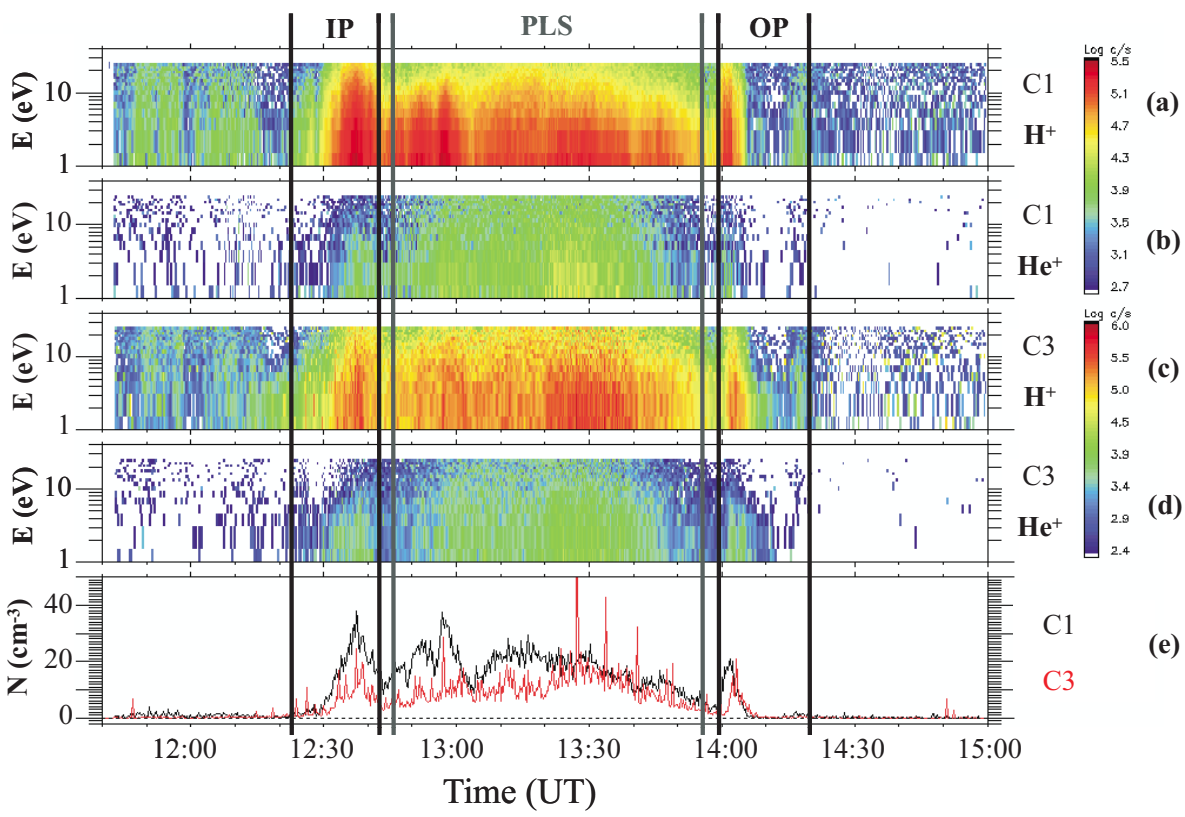

Fig. 10. Data from the CIS instrument in RPA mode on 2 June 2002 during the plasmasphere crossing of C1 and C3. Panels (a) and (b) show the distribution of $\mathrm{H}^{+}$and $\mathrm{He}^{+}$for $\mathrm{C} 1$, whereas the same data for $\mathrm{C} 3$ are shown on panels (c) and (d). Panel (e) shows $\mathrm{H}^{+}$density for C1 (black) and C3 (red).

between both edges of the plume: for the outer edge, $V_{N-e q}=4.2 \pm 0.8 \mathrm{~km} / \mathrm{s}, \phi \sim 30^{\circ}$, then $V_{P-e q}=8.4 \pm 1.6 \mathrm{~km} / \mathrm{s}$, whereas for the inner edge, $\mathrm{V}_{N-e q}=1.1 \pm 0.3 \mathrm{~km} / \mathrm{s}, \phi \sim 30^{\circ}$, then $V_{P-e q}=2.2 \pm 0.6 \mathrm{~km} / \mathrm{s}$. As in the preceding event, there are deviations from co-rotation.
Comparing both passes, the inner edge of the plume shifts $0.5 R_{E}$ in $75 \mathrm{~min}$, corresponding to $V_{I O-e q}=0.7 \pm 0.1 \mathrm{~km} / \mathrm{s}$. This is comparable to the projected radial boundary velocity, $V_{R-e q}$, which is $0.7 \pm 0.2 \mathrm{~km} / \mathrm{s}$ for the inbound pass and $1.3 \pm 0.2 \mathrm{~km} / \mathrm{s}$ for the outbound pass. For the outer edge 


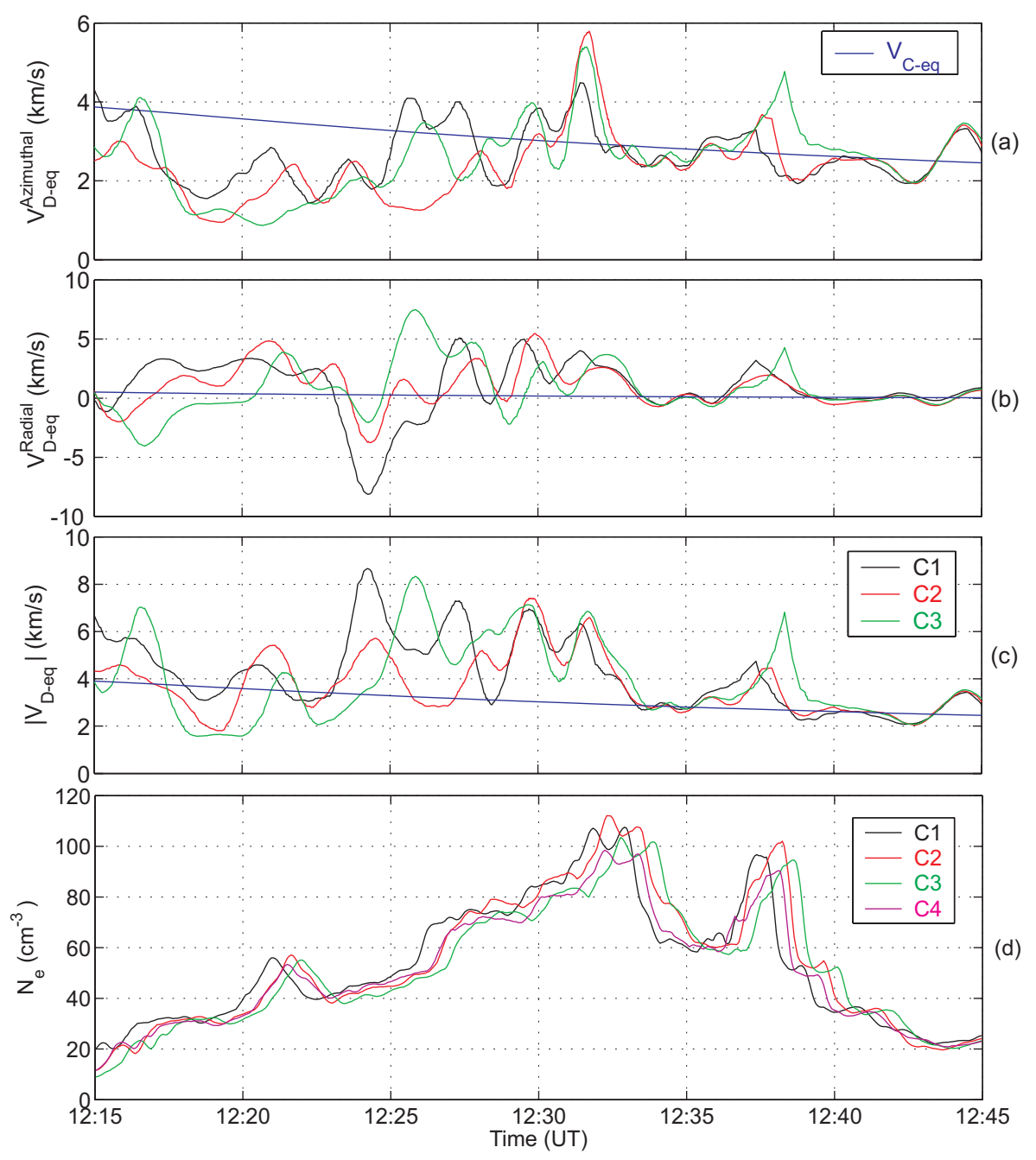

Fig. 11. Different quantities plotted as a function of time during the inbound plume crossing of 2 June 2002: (a)-(c) electron drift velocity $\boldsymbol{V}_{D-e q}$ measured by EDI onboard C1, C2 and C3 and projected onto the magnetic equatorial plane; (d) electron density determined from WHISPER onboard the four CLUSTER spacecraft (similar as panels (a)-(d) of Fig. 6).

of the plume, we found $V_{I O-e q}=0.5 \pm 0.1 \mathrm{~km} / \mathrm{s}$, whereas the timing analysis gives a value of $1.2 \pm 0.2 \mathrm{~km} / \mathrm{s}$ for the inbound crossing; for the outbound crossing, we obtain $V_{R-e q}=4.8 \pm 0.5 \mathrm{~km} / \mathrm{s}$, which is much higher. These results suggest that the plume is thinner in the outbound crossing in the Northern Hemisphere than in the inbound one in the Southern Hemisphere and that its inner edge is at a larger equatorial distance. They show also that the instantaneous measurements $\left(V_{N}\right)$ are in agreement with long term motion of the plume $\left(V_{I O-e q}\right)$.

Data from the CIS instrument in RPA mode $(0.7-25 \mathrm{eV} / \mathrm{q})$ are shown in Fig. 10 for $\mathrm{C} 1$ and C3. Panels (a)-(b) and (c)-(d) show the energy distribution of $\mathrm{H}^{+}$and $\mathrm{He}^{+}$for $\mathrm{C} 1$ and $\mathrm{C} 3$, respectively. Panel (e) plots the ion density for $\mathrm{C} 1$ and C3. The CLUSTER spacecraft enter the main plasmasphere at 12:45 UT and exit it at 13:55 UT, as indicated by higher proton density (PLS region). The plumes are clearly seen in the $\mathrm{H}^{+}$populations in the inbound crossing (IP) between 12:20 and 12:45 UT, and also in the outbound pass (OP) between 14:00 and 14:20 UT. The outbound plume seems to be divided in two parts, with lower ion densities in between. This density depletion corresponds to the decrease of electron density observed by WHISPER around 14:10 UT $\left(R_{\text {equat }} \sim 7.2 R_{E}\right.$ ). The plume crossings seem to be shorter in the $\mathrm{He}^{+}$spectrograms, because of the low densities in the outer part of the plumes. The density values obtained from CIS/CODIF in the RPA mode are lower than those determined from WHISPER because the limited energy range of the instrument does not cover the whole energy range of the ions (as can be seen in Fig. 10a and c) and because of spacecraft charging.

The drift velocity components determined by EDI are shown on Figs. 11a-c and 12a-c for C1, C2, C3, for the two plume crossings. Around the location of the maximum 


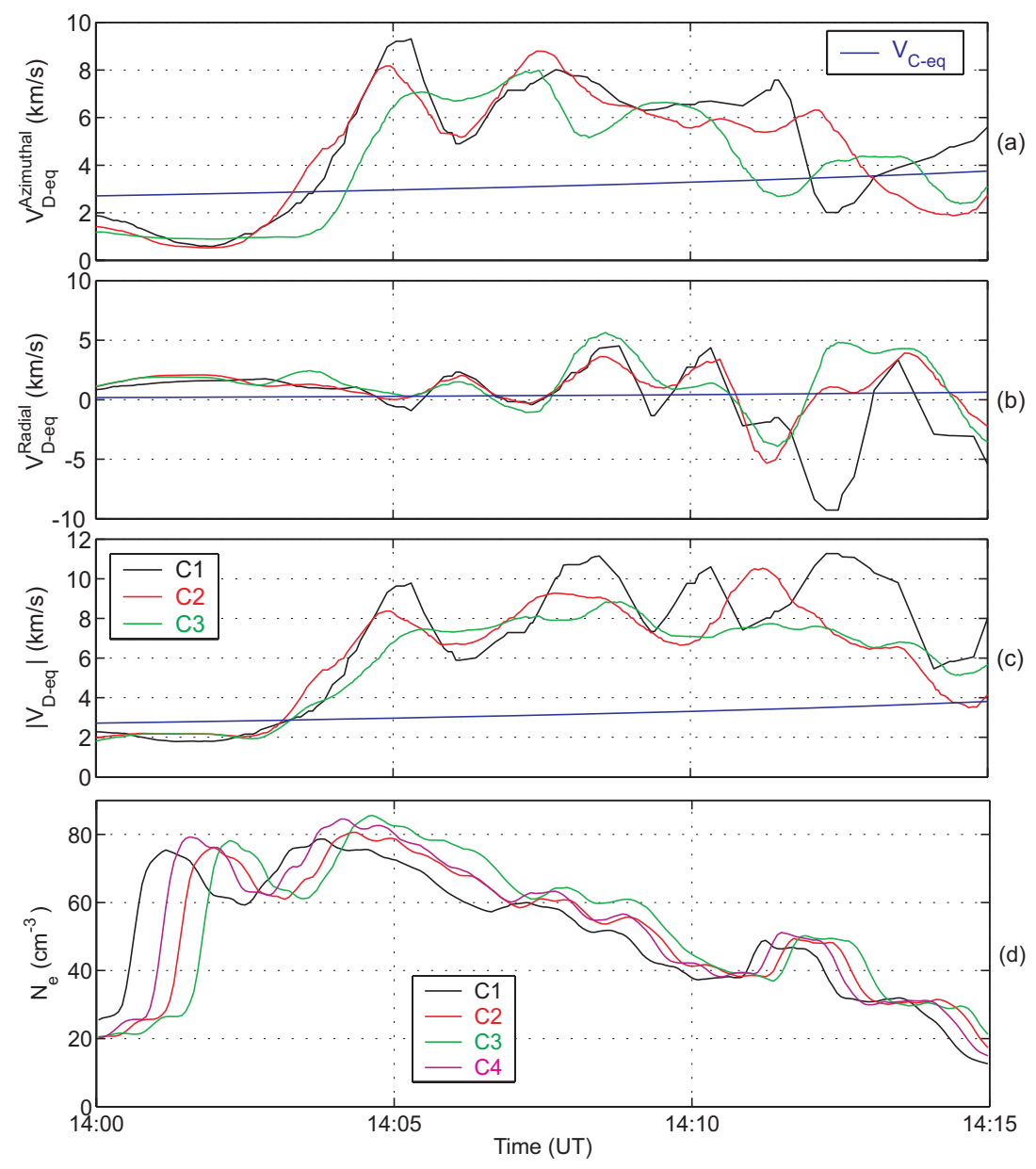

Fig. 12. Similar as Fig. 11 during the outbound plume crossing of 2 June 2002.

density (12:25 to $12: 35$ UT, and 14:07 to $14: 13$ UT), the velocity components have a wavy structure, but not as quasi-monochromatic as in the first plume event discussed in Sect. 3.1; the data again suggest that these non-compressional oscillations could be Alfvén waves. During the inbound plume crossing (see Fig. 11), the average equatorially projected electron drift velocity is $V_{D-e q}=3.5 \pm 1.0 \mathrm{~km} / \mathrm{s}$, mainly in the azimuthal direction but with also a radial expansion of the plume $(0.9 \mathrm{~km} / \mathrm{s})$. This magnitude is of the order of the co-rotation velocity $(3.6-2.4 \mathrm{~km} / \mathrm{s})$. Concerning the outbound crossing of the plume (see Fig. 12), $V_{D-e q}=5.5 \pm 1.0 \mathrm{~km} / \mathrm{s}$ on average, globally in the co-rotation direction, with larger values at the outer edge. This is consistent with the values of the velocity determined from WHISPER in the outbound plume. Inside the plasmasphere (12:50-13:50 UT, $\left.R_{\text {equat }}=4.4-5.3 R_{E}\right), V_{D-e q}=2.0 \pm 0.2 \mathrm{~km} / \mathrm{s}$, in the co-rotation direction and close to the co-rotation velocity $\left(V_{C-e q}=2.0\right.$ $2.3 \mathrm{~km} / \mathrm{s}$ ).

For this event, there is no noticeable change in the magnetic field.

\subsubsection{IMAGE and LANL observations}

Figure 13 presents an EUV image taken at 12:33 UT on 2 June 2002 (around the time of the inbound crossing of the plume by the CLUSTER satellites) and projected onto the dipole magnetic equatorial plane. A very large plume is observed in the post-dusk sector, with its foot attached to the plasmasphere between 17:30 and 22:00 MLT. At 17:30 MLT, it is located between 6.0 and $7.5 R_{E}$, which is consistent with WHISPER, which observes the plumes between 5.5 and $8.5 R_{E}$ (but with an electron density above the estimated EUV threshold only between 5.7 and $7.8 R_{E}$ ).

The plume is observed on EUV images from 10:10 UT until 14:30 UT. These successive images enable us to determine the motion of the plume. The foot of the plume (at $3.7 R_{E}$ ) moves at $V_{E}=1.6 \pm 0.1 \mathrm{~km} / \mathrm{s}$, close to the co-rotation velocity $V_{C-e q}=1.7 \mathrm{~km} / \mathrm{s}$. It is hard to make the same calculation with the tip of the plume, as it is difficult to identify the plume tip unambiguously. However, the tip is clearly moving slower than the foot. The images show that the tip is moving away from the Earth. The CLUSTER measurements also showed 


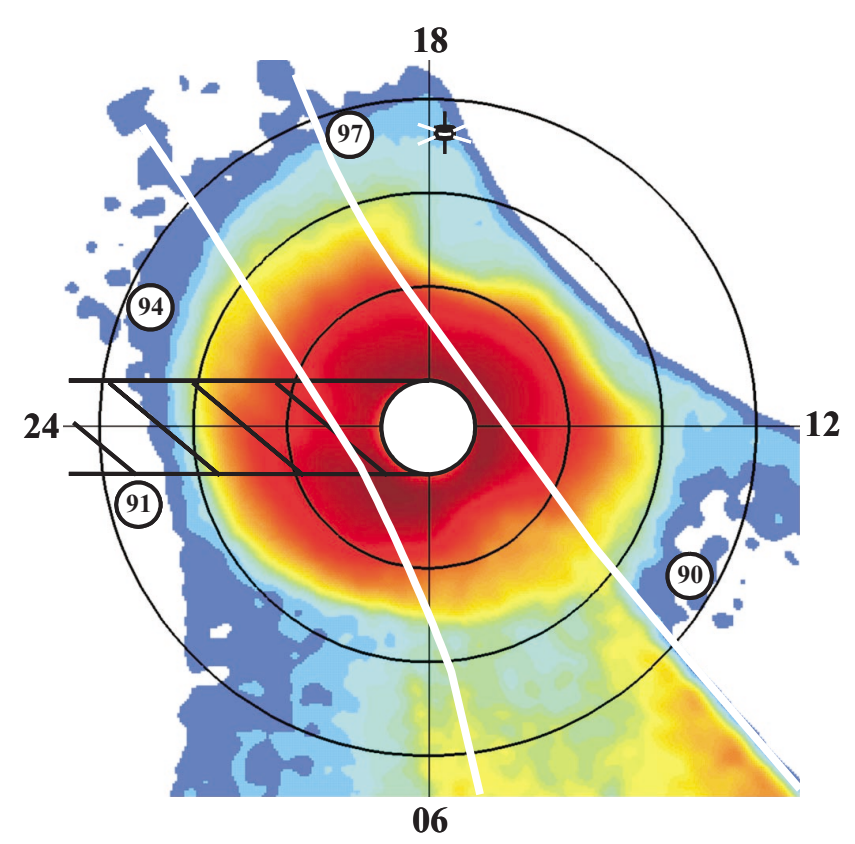

Fig. 13. Projection of a full-frame EUV image onto the equatorial plane at 12:33 UT on 2 June 2002 (similar as Fig. 7, with also the position of LANL 97A).

how the inner edge of the plume moves from $R_{\text {equat }}=5.6$ to $6 R_{E}$ between the inbound and outbound passes.

For this event, there is only one geosynchronous satellite (LANL 97A) that observes an increase of the ion density (up to $100 \mathrm{~cm}^{-3}$ ) at 19:00 MLT and around 12:30 UT; the three others are outside this MLT sector (see the position of LANL 1990-095, LANL 1991-080, LANL 1994-084 and LANL 97A on Fig. 13). The spacecraft observes this large density structure during $10 \mathrm{~h}$ as it orbits Earth from 12:00 to 22:00 MLT. This is consistent with the plume seen by IMAGE between 17:30 and 22:00 MLT, also with the high density value determined from CLUSTER (maximum electron density at about $100 \mathrm{~cm}^{-3}$ ), and with the equatorial distance where CLUSTER observes the plume at 12:30 UT: $6.5 R_{E}$.

\subsection{Third event: 11 April 2002}

\subsubsection{CLUSTER observations}

The third event on 11 April 2002 is located in the premidnight sector, between 21:45 and 21:10 MLT, and with a maximum value of $K_{p}$ in the previous $24 \mathrm{~h}$ equal to $3^{-}$. The CLUSTER spacecraft separation is around $150 \mathrm{~km}$. As this case has already been discussed by Darrouzet et al. (2004), we will summarize their results and complete them with input from other CLUSTER instruments and full-frame EUV images. Figure 14 displays WHISPER frequency-time spectrograms for the entire plasmasphere crossing. A plume is observed in the inbound (IP) and outbound (OP) passes, but the size and shape of this plume change considerably between both passes.

The electron density profiles given by Darrouzet et al. (2004, Fig. 4) allow the calculation of normal boundary velocities $\boldsymbol{V}_{N}$. After projection onto the equatorial plane, we find $V_{N-e q}=2.1 \pm 0.3 \mathrm{~km} / \mathrm{s}$ and $1.7 \pm 0.3 \mathrm{~km} / \mathrm{s}$ for the outer and inner edge of the inbound crossing respectively, and $V_{N-e q}=1.4 \pm 0.3 \mathrm{~km} / \mathrm{s}$ and $1.6 \pm 0.3 \mathrm{~km} / \mathrm{s}$ for the outer and inner edge of the outbound pass respectively. With $\phi \sim 15-20^{\circ}$ for the outer and inner edges of both crossings, the corresponding equatorial azimuthal velocities are $V_{P-e q}=8.1 \pm 1.2 \mathrm{~km} / \mathrm{s}$ and $5.0 \pm 0.8 \mathrm{~km} / \mathrm{s}$ for the inbound crossing, and $V_{P-e q}=4.1 \pm 0.9 \mathrm{~km} / \mathrm{s}$ and $6.2 \pm 1.1 \mathrm{~km} / \mathrm{s}$ for the outbound one (if the convection velocity would only be azimuthal). The co-rotation speed $V_{C-e q}$ ranges from 3.3 to $2.8 \mathrm{~km} / \mathrm{s}$ during the inbound crossing, and from 3.1 to $3.6 \mathrm{~km} / \mathrm{s}$ during the outbound one. This result could be also compatible with a lower azimuthal speed if there is an outward plasma motion as well. The calculation of $V_{I O-e q}$ from the displacement of a structure between the inbound and outbound passes confirms the previous calculations: for the inner edge, $V_{I O-e q}=0.7 \pm 0.1 \mathrm{~km} / \mathrm{s}$, whereas $V_{R-e q}=1.7 \pm 0.2 \mathrm{~km} / \mathrm{s}$, and for the outer edge, $V_{I O-e q}=0.4 \pm 0.1 \mathrm{~km} / \mathrm{s}$, whereas $V_{R-e q}=1.8 \pm 0.2 \mathrm{~km} / \mathrm{s}$. All these results show that the plume is moving outwards.

The CIS data in RPA mode are shown on Fig. 15 for C1 and $\mathrm{C} 3$. The format of this figure is the same as in Fig. 10. The plume is clearly detected on both spacecraft in the inbound pass around 04:30 UT (IP), and around 06:20 UT in the outbound one (OP). The ion composition differs in the plume and in the plasmaspheric core (PLS): there is fewer $\mathrm{H}^{+}$(panels a and c) and fewer $\mathrm{He}^{+}$(panels b and d) inside the plume than inside the inner plasmasphere, as in the two previous plume events. The extent of the plume along the spacecraft orbits is similar to that observed with WHISPER. In particular, there are two density peaks in the inbound plume crossing, consistent with the WHISPER spectrograms. The CIS density is again lower than that deduced from WHISPER (panel e), because of the spacecraft potential and the energy range limitations of the CIS instrument in RPA mode (a few $\mathrm{eV})$.

The drift velocities measured by EDI onboard C1, C2 and C3 during this plasmasphere crossing and projected onto the equatorial plane are displayed in Fig. 16. Inside the plasmasphere, the averaged drift speed $V_{D-e q}=2.4 \pm 0.2 \mathrm{~km} / \mathrm{s}$ is close to the co-rotation speed, $V_{C-e q}=2.0-2.5 \mathrm{~km} / \mathrm{s}$ in this region $\left(4.3-4.5 R_{E}\right)$. This velocity departs from $V_{C-e q}$ when the spacecraft move away from the magnetic equator crossed at 05:20 UT, which is expected when the spacecraft are in the outermost shells of the plasmasphere. The behaviour is different between both plume crossings: in the inbound pass, the drift velocity is again in the co-rotation direction with $V_{D-e q}=4.4 \pm 1.0 \mathrm{~km} / \mathrm{s}$, higher than the corotation speed at this position $\left(V_{C-e q}=2.8-3.3 \mathrm{~km} / \mathrm{s}\right)$. However, the drift velocity during the outbound crossing has a 


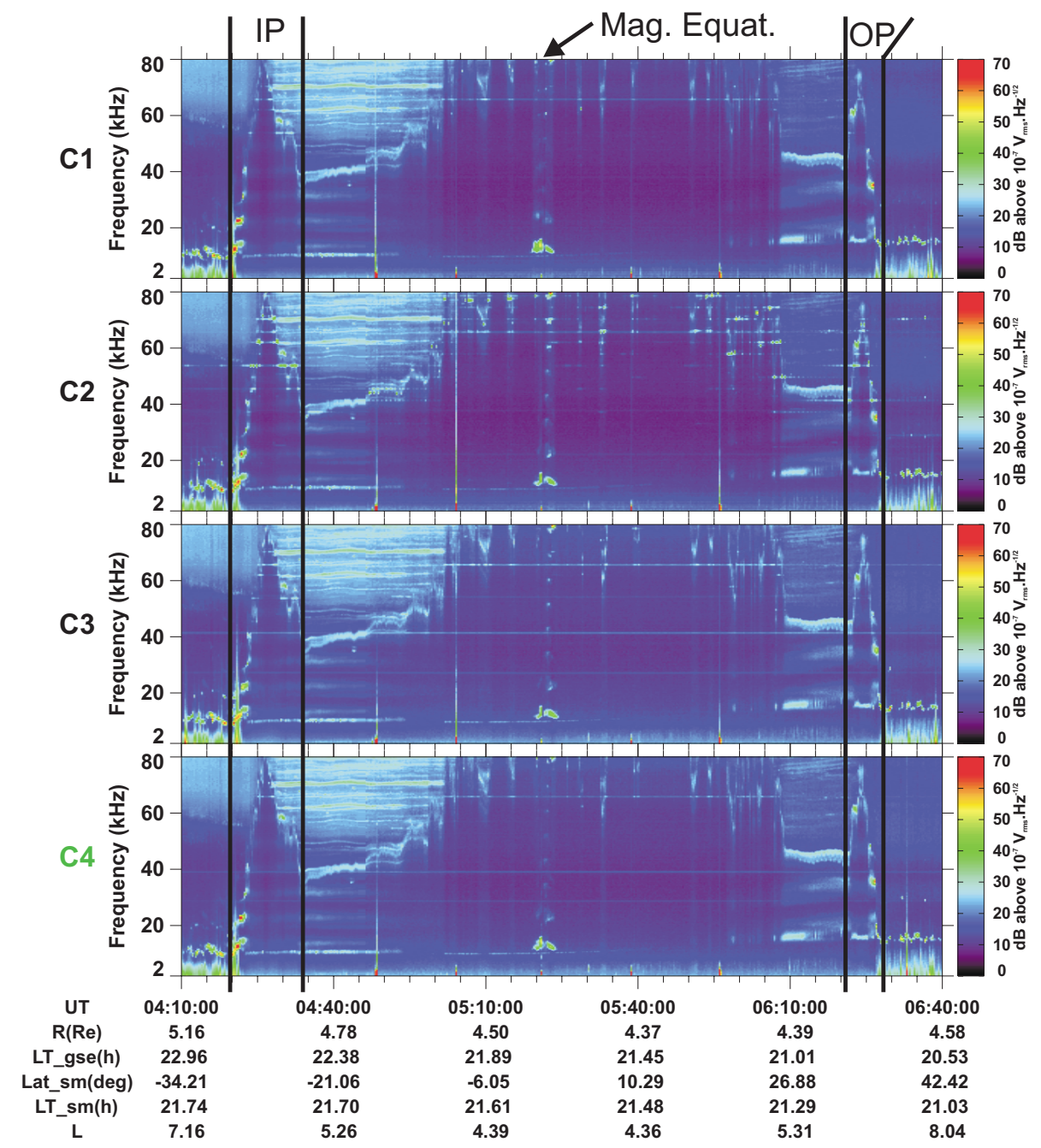

Fig. 14. Frequency-time spectrograms measured by the four CLUSTER/WHISPER instruments on 11 April 2002, showing the entire plasmasphere crossing, including plume traversals in the inbound (IP) and outbound passes (OP) and the magnetic equator (Mag. Equat.) crossed at 05:20 UT. The orbital parameters correspond to C4.

higher radial component $(1 \mathrm{~km} / \mathrm{s})$ and a lower magnitude $\left(V_{D-e q}=2.0 \pm 1.0 \mathrm{~km} / \mathrm{s}\right.$ on average $)$, except near the location of the maximum density inside the plume (as measured by WHISPER). There, the drift velocity $\boldsymbol{V}_{D-e q}$ is in the corotation direction. This is consistent with velocities determined from WHISPER (higher during the inbound pass than during the outbound one): it indicates again a slight outward radial motion of the plume.

During both plume crossings, we do not observe any variations in the magnetic field orientation (see FGM and modelled magnetic field on panels (b)-(e) of Figs. 16 and 17). However, there are significant variations just outside the inbound and outbound plume crossings delimited by the density profiles plotted as a function of time on panel (a) of Figs. 16 and 17.

\subsubsection{IMAGE and LANL observations}

EUV observations around the time of CLUSTER plume crossings are shown on Fig. 19. These full-frame EUV images, projected onto the dipole magnetic equatorial plane suggest that we deal here with a plume extending from the post-midnight towards the pre-midnight sector. As already shown by Darrouzet et al. (2004), the EUV results are consistent with WHISPER observations. For example, concerning the plasmapause position, the comparison between WHISPER and EUV gives a quite good correspondence. Indeed, in the pre-midnight sector (18:00-21:00 MLT), the plasmapause is around $4.5 R_{E}$ from EUV and $5 R_{E}$ from WHISPER. Moreover, the plume observed at 04:31 UT and 21:40 MLT extends from 6.4 to $7.1 R_{E}$ according to EUV, and from 6.2 to $7.2 R_{E}$ according to WHISPER (a bit broader as WHISPER is sensitive to lower densities). At 06:14 UT 


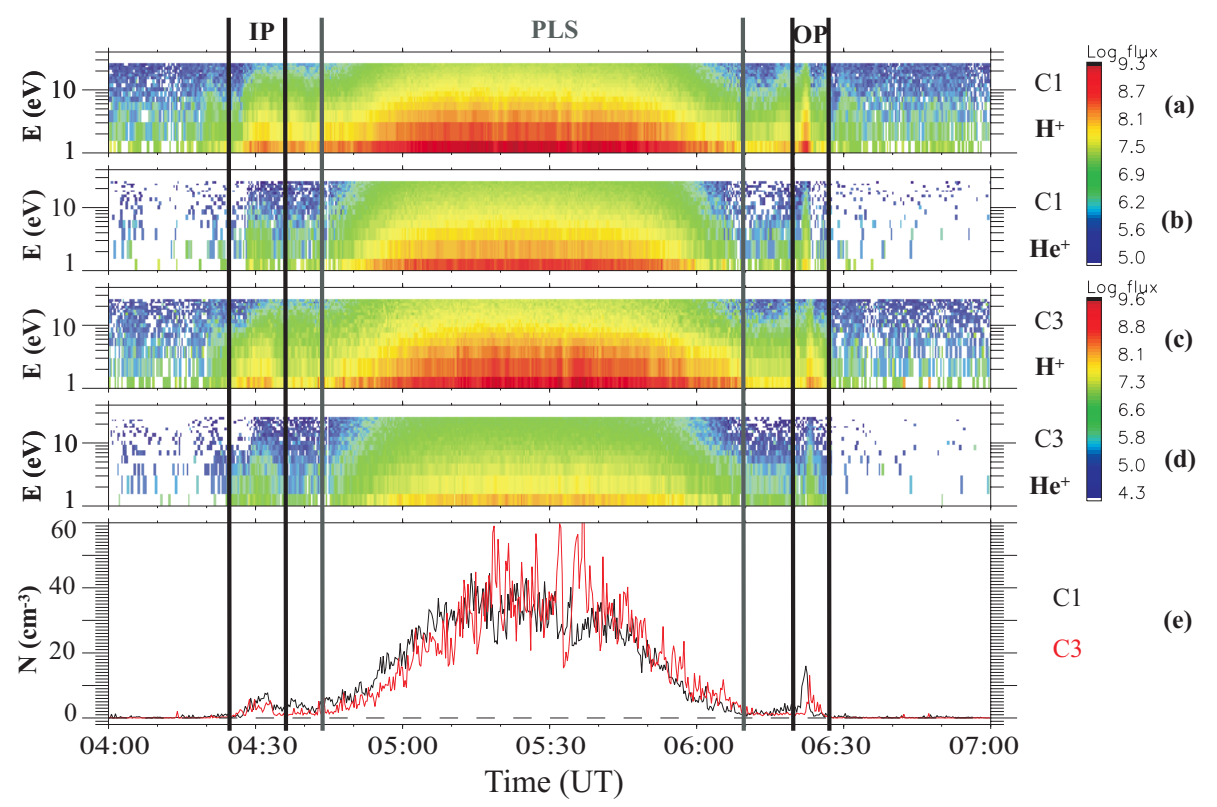

Fig. 15. Data from the CIS instrument in RPA mode on 11 April 2002 during the plasmasphere crossing of C1 and C3 (similar as Fig. 10).

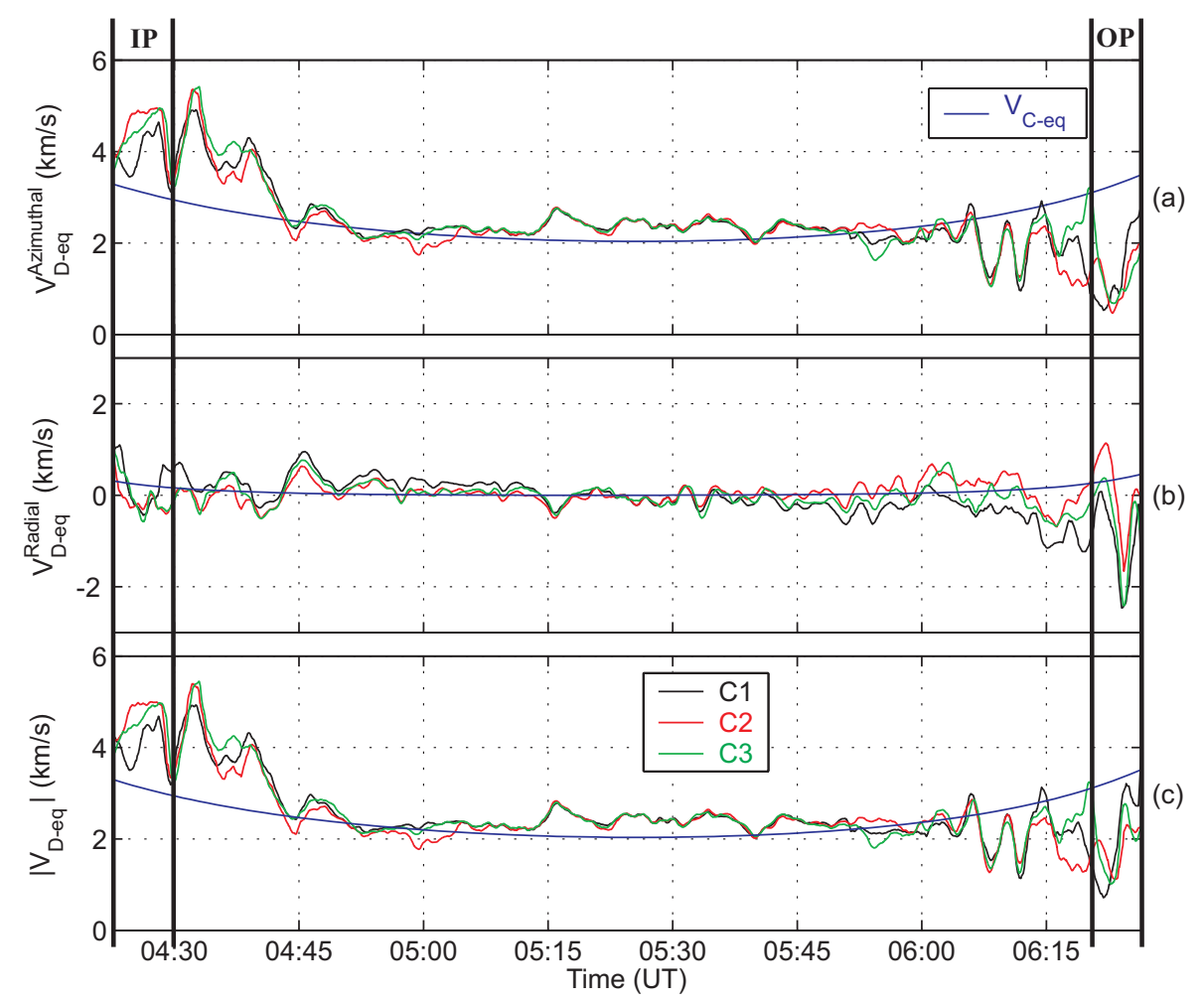

Fig. 16. Electron drift velocity $\boldsymbol{V}_{D-e q}$ measured by EDI and projected onto the magnetic equatorial plane during the plasmasphere crossing of 11 April 2002 (similar as Fig. 5), with the inbound plume crossing (IP) and the outbound one (OP).

and 21:10 MLT, EUV gives a transverse size of about $0.5 R_{E}$, and at 06:24 UT, WHISPER gives a value of $0.7 R_{E}$. The plume is observed in the EUV images for the first time around 01:30 UT, with its foot attached to the plasmasphere around 00:00 MLT, but it is in the shadow of the Earth, so it is quite difficult to locate precisely. It is visible until 08:00 UT, with its foot located around 06:00 MLT. This gives an approximate value for the motion of the foot of the plume (at 


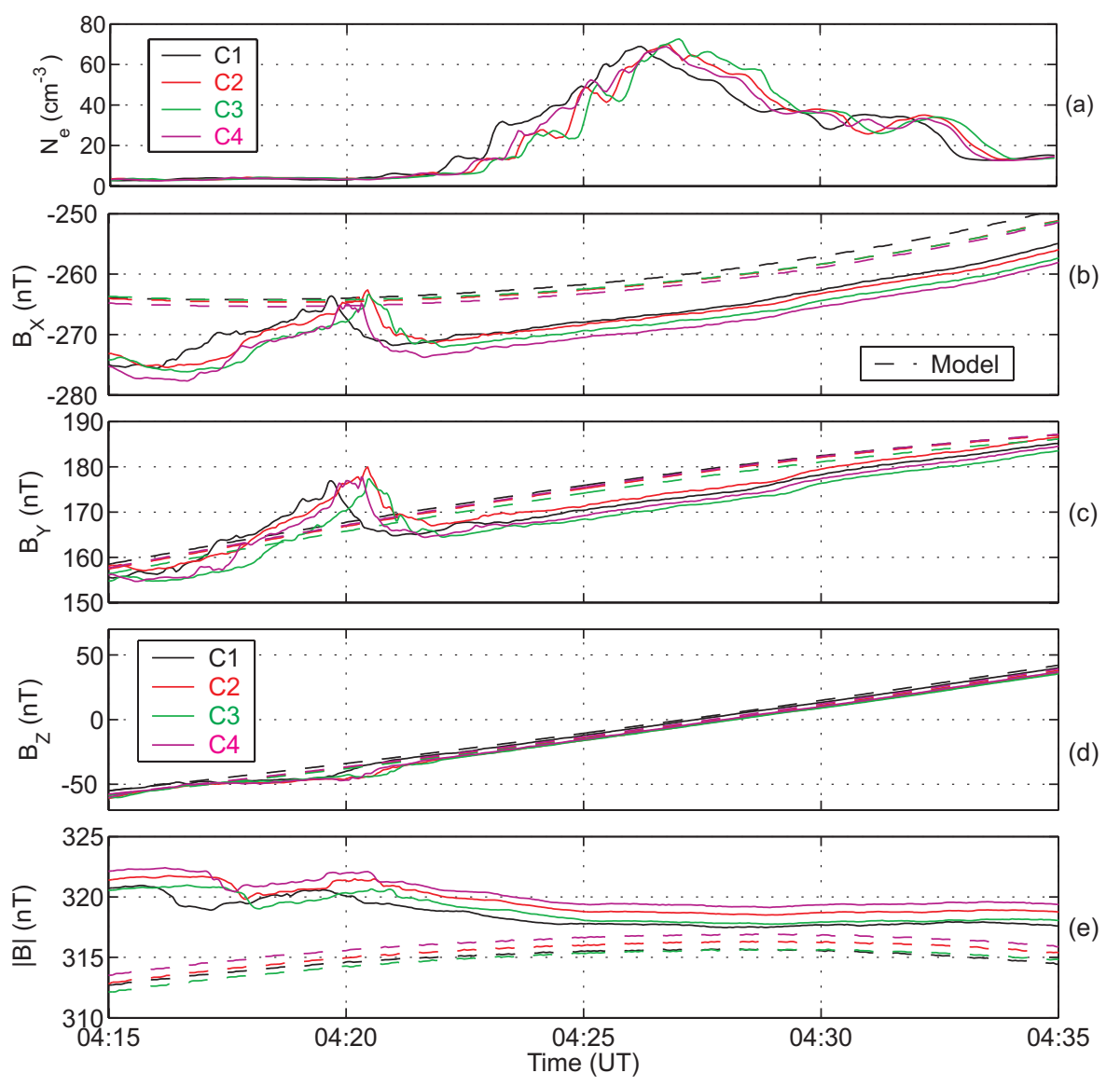

Fig. 17. Different quantities plotted as a function of time during the inbound plume crossing of 11 April 2002 (similar as panels (d)-(h) of Fig. 6).

$5.5 R_{E}$ ) of $V_{E}=2.3 \pm 0.1 \mathrm{~km} / \mathrm{s}$, slightly below the co-rotation speed $V_{C-e q}=2.5 \mathrm{~km} / \mathrm{s}$. Although the tip of the plume is almost outside the field of view of the EUV imager, successive images show that the tip of the plume moves at about half the co-rotation angular speed. There is also a small outward radial displacement of $0.2 R_{E}$ between 04:30 and 06:15 UT, but this radial motion seems to stop afterwards.

During this plasmasphere crossing, the LANL geosynchronous satellites available are not located in the MLT sectors where CLUSTER and IMAGE observe a plume, i.e. the pre-midnight sector (see the position of LANL 1990-095, LANL 1991-080 and LANL 1994-084 on Fig. 19). A slight ion density increase up to $20 \mathrm{~cm}^{-3}$ is observed by LANL 1994-084 around 20:00 MLT a few hours after the CLUSTER crossings, between 09:00 and 10:00 UT, which could be the tip of the plume.

\section{Summary and conclusions}

Three plasmasphere crossings have been presented in order to compare observations of plasmaspheric plumes by the
CLUSTER and IMAGE satellites. The CLUSTER and IMAGE missions are complementary, due to their different measurement techniques (global imaging with IMAGE and insitu high spatial resolution measurements with CLUSTER). They provide a more complete picture of the plasmasphere and in particular of plumes than any of them taken separately. The LANL geosynchronous satellites can complete this view of the plasmasphere at a fixed distance from the Earth.

The motion of the inner plasmasphere has been analysed with different tools and datasets. The inner shells of the plasmasphere are generally co-rotating with the angular velocity of the Earth. The drift velocity measured onboard CLUSTER departs from the co-rotation when the spacecraft move away from the magnetic equator. Some wavy structures with a period of $100 \mathrm{~s}$ have been sometimes observed. These oscillations could be Alfvén waves, but they need further study to be fully identified.

The three events exhibit different characteristics of plasmaspheric plumes, and the comparison between the global view from IMAGE and the in-situ measurements from CLUSTER gives consistent results concerning the radial position and MLT extend of the plumes (see a summary in 


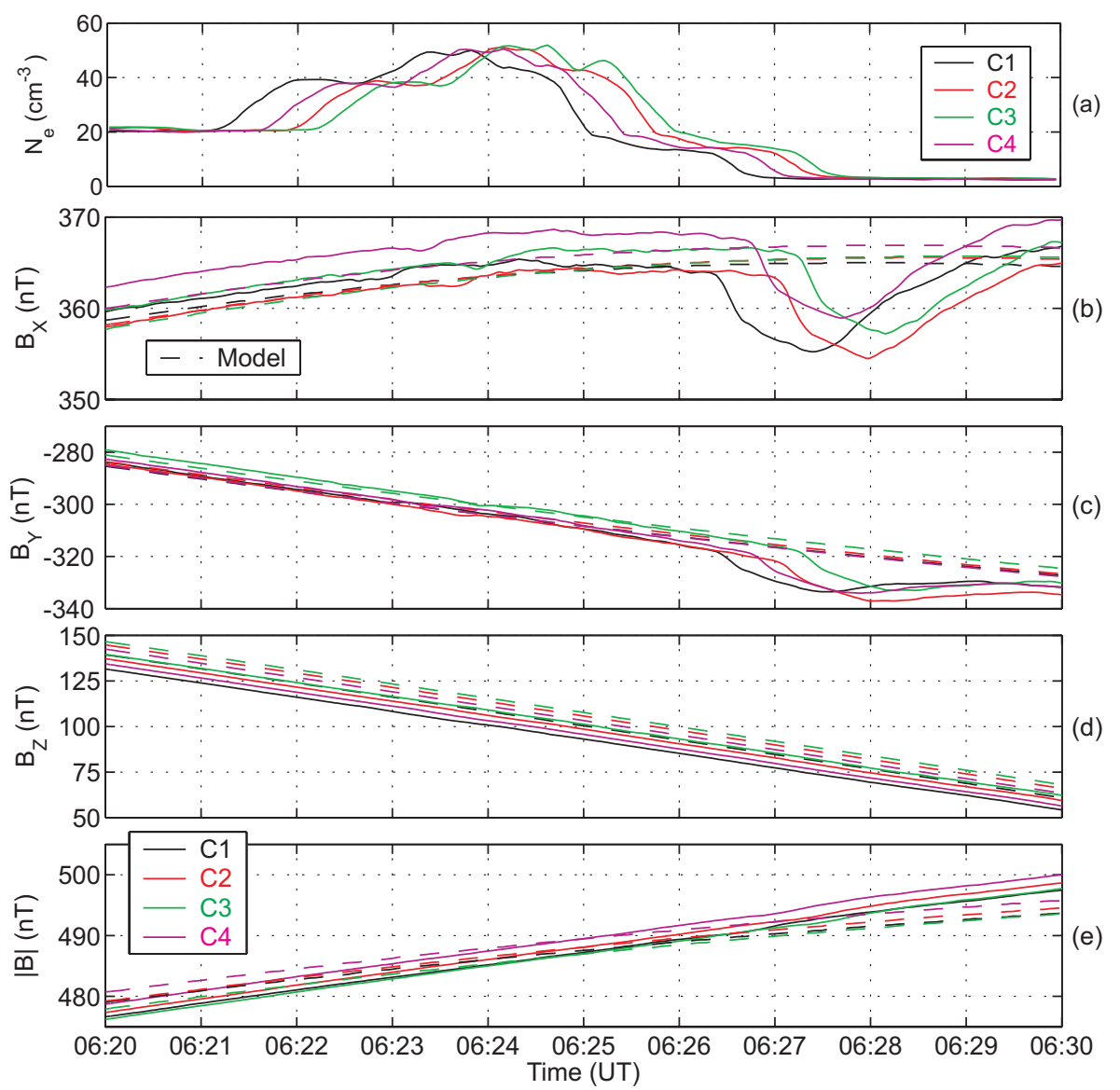

Fig. 18. Similar as Fig. 17 for the outbound plume crossing of 11 April 2002.

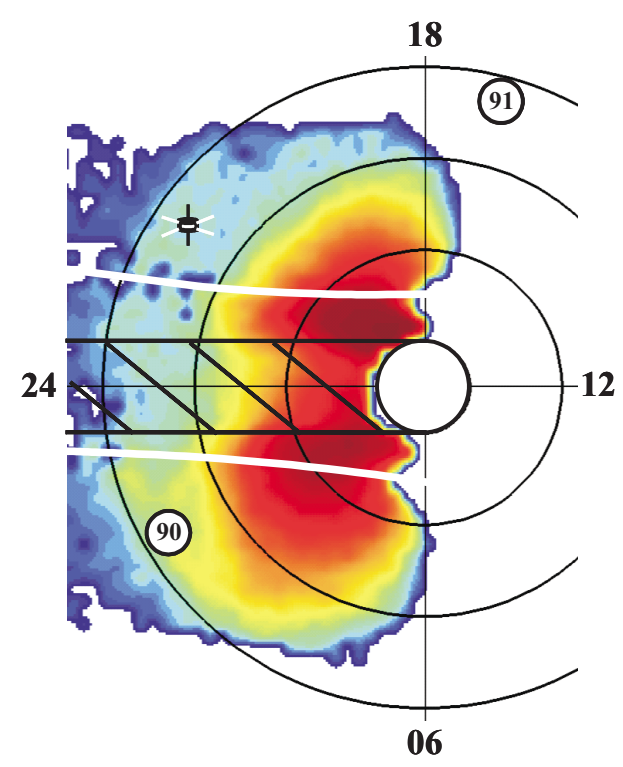

(a)

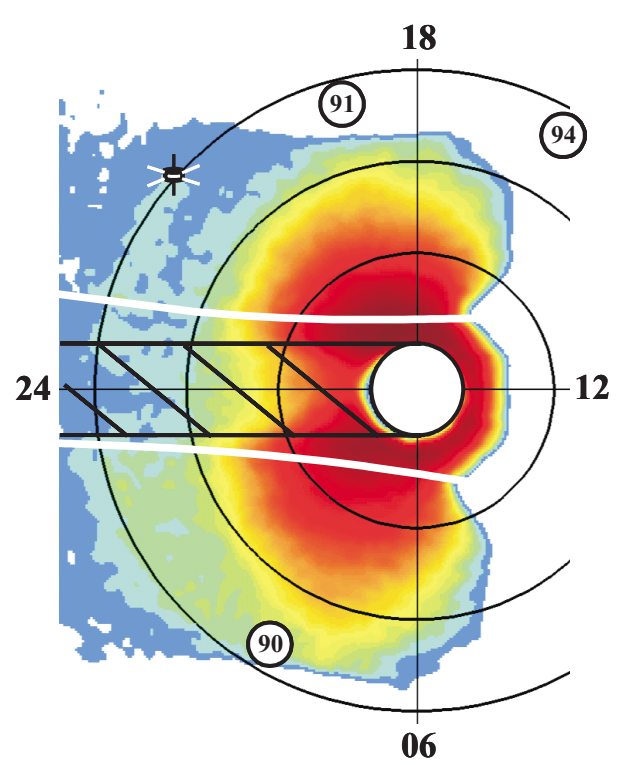

(b)

Fig. 19. Projection of a full-frame EUV image onto the magnetic equatorial plane on 11 April 2002 (a) at 04:31 UT, (b) at 06:14 UT (similar as Fig. 7). 
Table 2. Comparison between WHISPER and EUV for the three events about the radial distance of the plume and its MLT position.

Plume Radial Distance at the Equator $\left(\boldsymbol{R}_{E}\right)$ :

\begin{tabular}{|lcc|c|c|}
\hline \multicolumn{1}{|c}{ Date } & Time & MLT & WHISPER & EUV \\
\hline 7 May 2002 & 08:30 UT & 20:00 MLT & $7.3 \rightarrow 8.2$ & $7.0 \rightarrow 7.7$ \\
\hline 2 June 2002 & 12:30 UT & 17:45 MLT & $5.5 \rightarrow 8.5$ & $6.0 \rightarrow 7.5$ \\
\hline 11 April 2002 & 04:30 UT & $21: 40$ MLT & $6.2 \rightarrow 7.2$ & $6.4 \rightarrow 7.1$ \\
\hline 11 April 2002 & 06:20 UT & 21:10 MLT & $6.9 \rightarrow 7.6$ & $6.6 \rightarrow 7.1$ \\
\hline
\end{tabular}

Plume Position (MLT):

\begin{tabular}{|cl|c|c|}
\hline Date & Time & WHISPER & EUV \\
\hline 7 May 2002 & 08:30 UT & $20: 00$ & $20: 00-01: 00$ \\
\hline 2 June 2002 & 12:30 UT & $17: 45$ & $17: 30-22: 00$ \\
\hline 11 April 2002 & 04:30 UT & $21: 40$ & $20: 00-03: 00$ \\
\hline 11 April 2002 & 06:20 UT & $21: 10$ & $21: 00-04: 00$ \\
\hline
\end{tabular}

Table 3. Comparison between WHISPER and EUV for the three events about the plasmapause position.

\begin{tabular}{|ccc|c|c|}
\multicolumn{7}{|c}{ Plasmapause Position $\left(\boldsymbol{R}_{\boldsymbol{E}}\right):$} \\
\hline Date & Time & MLT & WHISPER & EUV \\
\hline 7 May 2002 & $08: 30$ UT & $18: 00-20: 00$ MLT & $<4.2$ & $3.7-4.0$ \\
\hline 2 June 2002 & $12: 30$ UT & $08: 00-10: 00$ MLT & No Data & $4.0-4.5$ \\
\hline 11 April 2002 & $06: 30$ UT & $18: 00-21: 00$ MLT & 5.0 & 4.5 \\
\hline
\end{tabular}

Table 4. Normal directions computed from the two different methods (density gradient and time delay), and projected normal boundary velocities for the three events.

\begin{tabular}{|c|c|c|c|}
\hline \multicolumn{4}{|c|}{ Normal Direction $\left({ }^{\circ}\right)$ and Normal Boundary Velocity $(\mathrm{km} / \mathrm{s})$ from WHISPER Data: } \\
\hline MLT & $\begin{array}{c}\text { Normal } \\
\text { Direction } \\
\text { (Density Gradient) }\end{array}$ & $\begin{array}{c}\text { Normal } \\
\text { Direction } \\
\text { (Time Delay) }\end{array}$ & $\begin{array}{c}\text { Normal Boundary } \\
\text { Velocity } V_{\text {N-eq }} \\
\text { (Time-Delay) }\end{array}$ \\
\hline 7 May $2002 \quad$ 20:00 MLT & Outer Edge: 180 & 08:35 UT: 15 & $2.3 \pm 0.5$ \\
\hline Inbound Plume & Inner Edge: 330 & 08:38 UT: 30 & $3.6 \pm 0.5$ \\
\hline 2 June 2002 & Outer Edge: 190 & 12:25 UT: 10 & $1.2 \pm 0.7$ \\
\hline Inbound Plume & Inner Edge: 340 & 12:32 UT: 10 & $0.7 \pm 0.2$ \\
\hline 2 June 2002 & Outer Edge: 190 & 14:15 UT: 30 & $4.2 \pm 0.8$ \\
\hline Outbound Plume & Inner Edge: 40 & 14:02 UT: 30 & $1.1 \pm 0.3$ \\
\hline 11 April $2002 \quad 21: 40$ MLT & Outer Edge: 190 & 04:21 UT: 15 & $2.1 \pm 0.3$ \\
\hline Inbound Plume & Inner Edge: 10 & 04:33 UT: 20 & $1.7 \pm 0.3$ \\
\hline 11 April 2002 21:10 MLT & Outer Edge: 190 & 06:26 UT: 20 & $1.4 \pm 0.3$ \\
\hline Outbound Plume & Inner Edge: 10 & 06:22 UT: 15 & $1.6 \pm 0.3$ \\
\hline
\end{tabular}

Table 2). Some plumes are very long and extend across a large MLT sector, up to 04:30 h MLT; their transverse size ranges from 0.5 to $1.5 R_{E}$, and their radial position varies from 5.5 to $8.5 R_{E}$. The plasmapause positions determined from WHISPER and EUV are also consistent (see Table 3). The normal directions of the plume boundaries, as computed using the density gradient tool and the time delay method, are generally consistent with each other (see a summary in Table 4), as well as with the EUV observations.

It is sometimes difficult to clearly detect the plume on EUV images because of its rather high instrumental density threshold $\left(40 \pm 10\right.$ electrons $\left.\mathrm{cm}^{-3}\right)$ : plumes usually have lower densities near the tip. Due to the high altitude of
CLUSTER's perigee, the satellites penetrate into the plasmasphere only for moderate to low $K_{p}$ (as indicated in an earlier study by Darrouzet et al., 2004). In any event, due to the upper frequency limitation of WHISPER $(80 \mathrm{kHz}$, corresponding to $80 \mathrm{~cm}^{-3}$ ), the observed plumes should not have too high density to be completely resolved (otherwise, densities can be inferred from the EFW spacecraft potential, which is, however, difficult to calibrate).

The ion composition is quite similar in all plume events, with a large amount of $\mathrm{H}^{+}$, some traces of $\mathrm{He}^{+}$, and no $\mathrm{O}^{+}$in the first event (no data for events 2 and 3). This is consistent with the results of the study by Dandouras et al. (2005). 
Table 5. Comparison between the velocities determined from EDI projected onto the equatorial plane and the projected co-rotation velocity for the three events.

\begin{tabular}{|c|c|c|}
\hline \multicolumn{3}{|c|}{ Projected Velocity $(\mathrm{km} / \mathrm{s})$ : } \\
\hline MLT & $\mathrm{V}_{\text {D-eq }}(\mathrm{EDI})$ & $\mathrm{V}_{\text {C-eq }}$ \\
\hline $\begin{array}{l}7 \text { May } 2002 \text { 20:00 MLT } \\
\text { Inbound Plume }\end{array}$ & $\begin{array}{c}\text { Azimuthal + Radial } \\
\text { Outer Edge: } 8.5 \pm 1.0 \\
\text { Inner Edge: } 6.8 \pm 1.0\end{array}$ & $\begin{array}{c}\text { Azimuthal } \\
3.8-3.4 \\
3.4-3.2\end{array}$ \\
\hline $\begin{array}{l}2 \text { June } 2002 \text { 17:45 MLT } \\
\text { Inbound Plume }\end{array}$ & $\begin{array}{c}\text { Azimuthal + Radial } \\
\text { Outer Edge: } 4.3 \pm 1.0 \\
\text { Inner Edge: } 2.8 \pm 1.0\end{array}$ & $\begin{array}{c}\text { Azimuthal } \\
3.6-2.8 \\
2.8-2.4\end{array}$ \\
\hline $\begin{array}{l}2 \text { June } 200218: 30 \text { MLT } \\
\text { Outbound Plume }\end{array}$ & $\begin{array}{c}\text { Azimuthal } \\
\text { Outer Edge: } 7.8 \pm 1.0 \\
\text { Inner Edge: } 3.0 \pm 1.0\end{array}$ & $\begin{array}{c}\text { Azimuthal } \\
2.9-3.6 \\
2.7-2.9\end{array}$ \\
\hline $\begin{array}{l}11 \text { April } 2002 \text { 21:40 MLT } \\
\text { Inbound Plume }\end{array}$ & $\begin{array}{c}\text { Azimuthal } \\
\text { Outer Edge: } 4.4 \pm 1.0 \\
\text { Inner Edge: } 4.4 \pm 1.0\end{array}$ & $\begin{array}{c}\text { Azimuthal } \\
3.3-3.0 \\
3.0-2.8\end{array}$ \\
\hline $\begin{array}{l}11 \text { April } 2002 \text { 21:10 MLT } \\
\text { Outbound Plume }\end{array}$ & $\begin{array}{c}\text { Azimuthal + Radial } \\
\text { Outer Edge: } 2.4 \pm 1.0 \\
\text { Inner Edge: } 1.7 \pm 1.0\end{array}$ & $\begin{array}{c}\text { Azimuthal } \\
3.3-3.6 \\
3.1-3.3\end{array}$ \\
\hline
\end{tabular}

The velocity analysis of the plumes gives consistent results with various techniques and different datasets. The results are summarized in Tables 4 and 5. The main conclusion is that the plume is rotating around the Earth, with its foot attached to the main plasmasphere fully co-rotating, but with its tip often rotating more slowly and moving outward, away from the Earth. This result is consistent with the topology of a plume, extending farther out at earlier MLT, as shown in earlier studies on plasmaspheric plumes (Spasojević et al., 2003; Darrouzet et al., 2004). As expected, closer to Earth, the plasma velocities are closer to co-rotation.

To conclude, this study allowed us to have a global idea about the formation, evolution and motion of plasmaspheric plumes from observations on various spacecraft, showing common features but also different aspects of these plumes. This study has been based on small spacecraft separation distance between the four CLUSTER satellites, but the large separation distances planned for the future will give another perspective on plumes, in particular on their evolution on longer time-scales.

Acknowledgements. The $B_{Y}, B_{Z}, D s t$ and $K_{p}$ indices as well as the solar wind pressure were provided by the Space Environment Information System (SPENVIS) website (http://www.spenvis.oma. be/spenvis/). The authors acknowledge the LANL data providers, M. Thomsen and the CDAWeb website (http://cdaweb.gsfc.nasa. gov/). The authors thank the referees for their thorough review of the paper and for their valuable suggestions. F. Darrouzet thanks M. Roth for helpful comments and careful reading of the manuscript, M. Kruglanski for his support with the UNILIB library (http://www.oma.be/NEEDLE/unilib.php) and X. Suraud for his help in computing WHISPER spectrograms. F. Darrouzet, J. De Keyser, and J. F. Lemaire acknowledge the support by the Belgian Federal Science Policy Office (BELSPO) through the
CLUSTER/PRODEX-8 project (contract 13127/98/NL/VJ (IC)). D. L. Gallagher acknowledges support from the NASA IMAGE mission. V. Pierrard acknowledges the support by BELSPO through the Action 1 grant MO/35/010. B. R. Sandel acknowledges support under NASA contract NAS5-96020. H. Matsui acknowledges the support by NASA through grant NNG04GA46G.

Topical Editor I. A. Daglis thanks M. Thomsen and J. Burch for their help in evaluating this paper.

\section{References}

Balogh, A., Carr, C. M., Acuña, M. H., Dunlop, M. W., Beek, T. J., Brown, P., Fornaçon, K.-H., Georgescu, E., Glassmeier, K.H., Harris, J., Musmann, G., Oddy, T., and Schwingenschuh, K.: The Cluster Magnetic Field Investigation: overview of in-flight performance and initial results, Ann. Geophys., 19, 1207-1217, 2001.

Bame, S. J., McComas, D. J., Thomsen, M. F., Barraclough, B. L., Elphic, R. C., Glore, J. P., Gosling, J. T., Chavez, J. C., Evans, E. P., and Wymer, F. J.: Magnetospheric plasma analyzer for spacecraft with constrained resources, Rev. Sci. Instrum., 64(4), 10261033, 1993.

Burch, J. L.: IMAGE mission overview, Space Sci. Rev., 91, 1-14, 2000.

Canu, P., Décréau, P. M. E., Trotignon, J. G., Rauch, J. L., Seran, H. C., Fergeau, P., Lévêque, M., Martin, Ph., Sené, F. X., Le Guirriec, E., Alleyne, H., and Yearby, K.: Identification of natural plasma emissions observed close to the plasmapause by the Cluster-Whisper relaxation sounder, Ann. Geophys., 19, 16971709, 2001.

Carpenter, D. L., Smith, A. J., Giles, B. L., Chappell, C. R., and Décréau, P. M. E.: A case study of plasma structure in the dusk sector associated with enhanced magnetospheric convection, J. Geophys. Res., 97(A2), 1157-1166, 1992. 
Carpenter, D. L.: Remote sensing the Earth's plasmasphere, Rad. Sci. Bull., 308, 13-29, 2004.

Carpenter, D. L. and Lemaire, J.: The Plasmasphere Boundary Layer, Ann. Geophys., 22, 4291-4298, 2004.

Chappell, C. R., Harris, K. K., and Sharp, G. W.: The morphology of the bulge region of the plasmasphere, J. Geophys. Res., 75, 3848-3861, 1970.

Chappell, C. R.: Detached plasma regions in the magnetosphere, J. Geophys. Res., 79, 1861-1870, 1974.

Chen, A. J. and Wolf, R. A.: Effects on the plasmasphere of a timevarying convection electric field, Planet. Space Sci., 20, 483509, 1972.

Chen, A. J. and Grebowsky, J. M.: Plasma tail interpretations of pronounced detached plasma regions measured by Ogo 5, J. Geophys. Res., 79, 3851-3855, 1974.

Dandouras, I., Pierrard, V., Goldstein, J., Vallat, C., Parks, G. K., Rème, H., Gouillart, C., Sevestre, F., McCarthy, M., Kistler, L. M., Klecker, B., Korth, A., Bavassano-Cattaneo, M. B., Escoubet, P., and Masson, A.: Multipoint Observations of Ionic Structures in the Plasmasphere by CLUSTER-CIS and Comparisons With IMAGE-EUV Observations and With Model Simulations, in: Inner Magnetosphere Interactions: New Perspectives from Imaging, edited by: Burch, J., Schulz, M., and Spence, H., Geophysical Monograph Series, 159, AGU Washington D.C., 23-53, 2005.

Darrouzet, F., Décréau, P. M. E., De Keyser, J., Masson, A., Gallagher, D. L., Santolik, O., Sandel, B. R., Trotignon, J. G., Rauch, J. L., Le Guirriec, E., Canu, P., Sedgemore, F., André, M., and Lemaire, J. F.: Density structures inside the plasmasphere: Cluster observations, Ann. Geophys., 22, 2577-2585, 2004.

Darrouzet, F., De Keyser, J., Décréau, P. M. E., Lemaire, J. F., and Dunlop, M. W.: Spatial gradients in the plasmasphere from Cluster, Geophys. Res. Lett., 33, L08105, doi:10.1029/2006GL025727, 2006.

Décréau, P. M. E., Fergeau, P., Krasnoselskikh, V., Lévêque, M., Martin, Ph., Randriamboarison, O., Sené, F. X., Trotignon, J. G., Canu, P., Mögensen, P. B., and Whisper investigators: Whisper, a resonance sounder and wave analyser: performances and perspectives for the Cluster mission, Space Sci. Rev., 79, 157-193, 1997.

Décréau, P. M. E., Fergeau, P., Krasnoselskikh, V., Le Guirriec, E., Lévêque, M., Martin, Ph., Randriamboarison, O., Rauch, J. L., Sené, F. X., Séran, H. C., Trotignon, J. G., Canu, P., Cornilleau, N., de Féraudy, H., Alleyne, H., Yearby, K., Mögensen, P. B., Gustafsson, G., André, M., Gurnett, D. A., Darrouzet, F., Lemaire, J., Harvey, C. C., Travnicek, P., and Whisper experimenters: Early results from the Whisper instrument on CLUSTER: an overview, Ann. Geophys., 19, 1241-1258, 2001.

Décréau, P. M. E., Ducoin, C., Le Rouzic, G., Randriamboarison, O., Rauch, J. L., Trotignon, J. G., Vallières, X., Canu, P., Darrouzet, F., Gough, M. P., Buckley, A.M., and Carozzi, T. D.: Observation of Continuum radiations from the CLUSTER fleet: first results from direction finding, Ann. Geophys., 22, 2607-2624, 2004.

Décréau, P. M. E., Le Guirriec, E., Rauch, J. L., Trotignon, J. G., Canu, P., Darrouzet, F., Lemaire, J., Masson, A., Sedgemore, F., and André, M.: Density irregularities in the plasmasphere boundary player: Cluster observations in the dusk sector, Adv. Space Res., 36(10), 1964-1969, 2005.
Elphic, R. C., Weiss, L. A., Thomsen, M. F., McComas, D. J., and Moldwin, M. B.: Evolution of plasmaspheric ions at geosynchronous orbit during times of high geomagnetic activity, Geophys. Res. Lett., 23(16), 2189-2192, 1996.

Escoubet, C. P., Russell, C. T., and Schmidt, R. (Eds.): The Cluster and Phoenix Missions, Kluwer Academic Publishers, 658, 1997.

Foster, J. C., Erickson, P. J., Coster, A. J., Goldstein, J., and Rich, F. J.: Ionospheric signatures of plasmaspheric tails, Geophys. Res. Lett., 29(13), 1623, doi:10.1029/2002GL015067, 2002.

Gallagher, D. L., Adrian, M. L., and Liemohn, M. W.: The origin and evolution of deep plasmaspheric notches, J. Geophys. Res., 110, A06201, doi:10.1029/2004JA010906, 2005.

Ganguli, G., Reynolds, M. A., and Liemohn, M. W.: The plasmasphere and advances in plasmaspheric research, J. Atm. SolarTerr. Phys., 62, 1647-1657, 2000.

Garcia, L. N., Fung, S. F., Green, J. L., Boardsen, S. A., Sandel, B. R., and Reinisch, B. W.: Observations of the latitudinal structure of plasmaspheric convection plumes by IMAGE-RPI and EUV, J. Geophys. Res., 108, 1321, doi:10.1029/2002JA009496, 2003.

Goldstein, J., Sandel, B. R., Hairston, M. R., and Reiff, P. H.: Control of plasmaspheric dynamics by both convection and subauroral polarization stream, Geophys. Res. Lett.,30(24), 2243, doi:10.1029/2003GL018390, 2003a.

Goldstein, J., Spasojević, M., Reiff, P. H., Sandel, B. R., Forrester, W. T., Gallagher, D. L., and Reinisch, B. W.: Identifying the plasmapause in IMAGE EUV data using IMAGE RPI in situ steep density gradients, J. Geophys. Res., 108, 1147, doi:10.1029/2002JA009475, 2003b.

Goldstein, J., Sandel, B. R., Thomsen, M. F., Spasojević, M., and Reiff, P. H.: Simultaneous remote sensing and in situ observations of plasmaspheric drainage plumes, J. Geophys. Res., 109, A03202, doi:10.1029/2003JA010281, 2004.

Goldstein, J. and Sandel, B. R.: The Global Pattern of Evolution of Plasmaspheric Drainage Plumes, in: Inner Magnetosphere Interactions: New Perspectives from Imaging, edited by: Burch, J., Schulz, M., and Spence, H., Geophysical Monograph Series, 159, AGU Washington D.C., 1-22, 2005.

Grebowsky, J. M.: Model study of plasmapause motion, J. Geophys. Res., 75, 4329-4333, 1970.

Gustafsson, G., André, M., Carozzi, T., Eriksson, A. I., Fälthammar, C.-G., Grard, R., Holmgren, G., Holtet, J. A., Ivchenko, N., Karlsson, T., Khotyaintsev, Y., Klimov, S., Laakso, H., Lindqvist, P.-A., Lybekk, B., Marklund, G., Mozer, F., Mursula, K., Pedersen, A., Popielawska, B., Savin, S., Stasiewicz, K., Tanskanen, P., Vaivads, A., and Wahlund, J.-E.: First results of electric field and density observations by Cluster EFW based on initial months of observations, Ann. Geophys., 19, 1219-1240, 2001.

Harvey, C. C.: Spatial gradient and the volumetric tensor; in Analysis methods for Multi-Spacecraft data, edited by: Paschmann, G and Daly, P. W., ISSI scientific Report SR-001, 307-322, 1998.

Laakso, H. and Pedersen, A.: Ambient electron density derived from differential potential measurements, in: Measurements Techniques in Space Plasmas, edited by: Borovsky, J., Pfaff, P., and Young, D., Geophysical Monograph Series, 102, AGU Washington D.C., 49-54, 1998.

Lemaire, J. F. and Gringauz, K. I.: The Earth's Plasmasphere, with contributions from D. L. Carpenter and V. Bassolo, Cambridge University Press, New York, 372, 1998. 
Lemaire, J. F.: The formation plasmaspheric tails, Phys. Chem. Earth (C), 25, 9-17, 2000.

Lemaire, J. F.: The formation of the light-ion-trough and peeling off the plasmasphere, J. Atmos. Terr. Phys., 63, 1285-1291, 2001.

Matsui, H., Quinn, J. M., Torbert, R. B., Jordanova, V. K., Baumjohann, W., Puhl-Quinn, P. A., and Paschmann, G.: Electric field measurements in the inner magnetosphere by Cluster EDI, J. Geophys. Res., 108, 1352, doi:10.1029/2003JA009913, 2003.

Matsui, H., Jordanova, V. K., Quinn, J. M., Torbert, R. B., and Paschmann, G.: Derivation of electric potential patterns in the inner magnetosphere from Cluster EDI data: Initial results, J. Geophys. Res., 109, A10202, doi:10.1029/2003JA010319, 2004.

McIlwain, C. E.: Coordinates for Mapping the Distribution of Magnetically Trapped Particles, J. Geophys. Res., 66, 3681-3691, 1961.

Moldwin, M. B., Howard, J., Sanny, J., Bocchicchio, J. D., Rassoul, H. K., and Anderson, R. R.: Plasmaspheric plumes: CRRES observations of enhanced density beyond the plasmapause, J. Geophys. Res., 109, A05202, doi:10.1029/2003JA010320, 2004.

Moullard, O., Masson, A., Laakso, H., Parrot, M., Décréau, P. M. E., Santolik, O., and André, M.: Density modulated whistler mode emissions observed near the plasmapause, Geophys. Res. Lett., 29(20), doi:10.1029/2002GL015101, 2002.

Ober, D. M., Horwitz, J. L., Thomsen, M. F., Elphic, R. C., McComas, D. J., Belian, R. D., and Moldwin, M. B.: Premidnight plasmaspheric “plumes", J. Geophys. Res., 102(A6), 11 325-11334, 1997.

Paschmann, G., Quinn, J. M., Torbert, R. B., Vaith, H., McIlwain, C. E., Haerendel, G., Bauer, O. H., Bauer, T., Baumjohann, W., Fillius, W., Förster, M., Frey, S., Georgescu, E., Kerr, S. S., Kletzing, C. A., Matsui, H., Puhl-Quinn, P., and Whipple, E. C.: The Electron Drift Instrument on Cluster: overview of first results, Ann. Geophys., 19, 1273-1288, 2001.

Pedersen, A.: Solar wind and magnetosphere plasma diagnostics by spacecraft electrostatic potential measurements, Ann. Geophys., 13, 118-129, 1995.

Pedersen, A., Décréau, P., Escoubet, C. P., Gustafsson, G., Laakso, H., Lindqvist, P.-A., Lybekk, B., Masson, A., Mozer, F., and Vaivads, A.: Four-point high resolution information on electron densities by the electric field experiments (EFW) on Cluster, Ann. Geophys., 19, 1483-1489, 2001.

Pierrard, V. and Lemaire, J. F.: Development of shoulders and plumes in the frame of the interchange instability mechanism for plasmapause formation, Geophys. Res. Lett., 31, L05809, doi:10.1029/2003GL018919, 2004.

Pierrard, V. and Cabrera, J.: Comparisons between EUV/IMAGE observations and numerical simulations of the plasmapause formation, Ann. Geophys., 23, 2635-2646, 2005.

Rème, H., Aoustin, C., Bosqued, J. M., Dandouras, I., Lavraud, B., Sauvaud, J. A., Barthe, A., Bouyssou, J., Camus, Th., CoeurJoly, O., Cros, A., Cuvilo, J., Ducay, F., Garbarowitz, Y., Médale, J. L., Penou, E., Perrier, H., Romefort, D., Rouzaud, J., Vallat, C., Alcaydé, D., Jacquey, C., Mazelle, C., d’Uston, C., Möbius, E., Kistler, L. M., Crocker, K., Granoff, M., Mouikis, C., Popecki, M., Vosbury, M., Klecker, B., Hovestadt, D., Kucharek, H., Kuenneth, E., Paschmann, G., Scholer, M., Sckopke, N., Seidenschwang, E., Carlson, C. W., Curtis, D. W., Ingraham, C., Lin, R. P., McFadden, J. P., Parks, G. K., Phan, T., Formisano, V., Amata, E., Bavassano-Cattaneo, M. B., Baldetti, P., Bruno, R., Chion- chio, G., Di Lellis, A., Marcucci, M. F., Pallocchia, G., Korth, A., Daly, P. W., Graeve, B., Rosenbauer, H., Vasyliunas, V., McCarthy, M., Wilber, M., Eliasson, L., Lundin, R., Olsen, S., Shelley, E. G., Fuselier, S., Ghielmetti, A. G., Lennartsson, W., Escoubet, C. P., Balsiger, H., Friedel, R., Cao, J-B., Kovrazhkin, R. A., Papamastorakis, I., Pellat, R., Scudder, J., and Sonnerup, B.: First multi-spacecraft ion measurements in and near the Earth's magnetosphere with the identical Cluster ion spectrometry (CIS) experiment, Ann. Geophys., 19, 1303-1354, 2001.

Roelof, E. C. and Skinner, A. J.: Extraction of ion distributions from magnetospheric ENA and EUV images, Space Sci. Rev., 91, 437-459, 2000.

Sandel, B. R., Broadfoot, A. L., Curtis, C. C., King, R. A., Stone, T. C., Hill, R. H., Chen, J., Siegmund, O. H. W., Raffanti, R., Allred, D. D., Turley, R. S., and Gallagher, D. L.: The extreme ultraviolet imager investigation for the IMAGE mission, Space Sci. Rev., 91, 197-242, 2000.

Sandel, B. R., King, R. A., Forrester, W. T., Gallagher, D. L., Broadfoot, A. L., Curtis, C. C.: Initial Results from the IMAGE Extreme Ultraviolet Imager, Geophys. Res. Lett., 28(8), 14391442, 2001.

Sandel, B. R., Goldstein, J., Gallagher, D. L., and Spasojević, M.: Extreme ultraviolet imager observations of the structure and dynamics of the plasmasphere, Space Sci. Rev., 109, 25-46, 2003.

Spasojević, M., Goldstein, J., Carpenter D. L., Inan, U. S., Sandel, B. R., Moldwin, M. B., and Reinisch, B. W.: Global response of the plasmasphere to a geomagnetic disturbance, J. Geophys. Res., 108, 1340, doi:10.1029/2003JA009987, 2003.

Spasojević, M., Frey, H. U., Thomsen, M. F., Fuselier, S. A., Gary, S. P., Sandel, B. R., and Inan, U. S.: The link between a detached subauroral proton arc and a plasmaspheric plume, Geophys. Res. Lett., 31, L04803, doi:10.1029/2003GL018389, 2004.

Taylor Jr., H. A., Grebowsky, J. M., and Walsh, W. J.: Structured Variations of the Plasmapause: Evidence of a corotating plasma tail, J. Geophys. Res., 76, 6806-6814, 1971.

Tobiska, W. K., Woods, T., Eparvier, F., Viereck, R., Floyd, L., Bouwer, D., Rottman, G., and White, O. R.: The SOLAR2000 empirical solar irradiance model and forecast tool, J. Atmos. Terr. Phys., 62, 1233-1250, 2000.

Trotignon, J. G., Décréau, P. M. E., Rauch, J. L., Randriamboarison, O., Krasnoselskikh, V., Canu, P., Alleyne, H., Yearby, K., Le Guirriec, E., Séran, H. C., Sené, F. X., Martin, Ph., Lévêque, M., and Fergeau, P.: How to determine the thermal electron density and the magnetic field strength from the CLUSTER/WHISPER observations around the Earth, Ann. Geophys., 19, 1711-1720, 2001.

Trotignon, J. G., Décréau, P. M. E., Rauch, J. L., Le Guirriec, E., Canu, P., and Darrouzet, F.: The Whisper Relaxation Sounder Onboard Cluster: A Powerful Tool for Space Plasma Diagnosis around the Earth, Cosmic Research, 41(4), 369-372, 2003.

Tsyganenko, N. A. and Stern, D. P.: Modeling the global magnetic field of the large-scale Birkeland current systems, J. Geophys. Res., 101(A12), 27 187-27 198, 1996.

Weiss, L. A., Lambour, R. L., Elphic, R. C., and Thomsen, M. F.: Study of plasmaspheric evolution using geosynchronous observations and global modeling, Geophys. Res. Lett., 24(5), 599602, 1997. 